Article

\title{
An Empirical Model for the Effect of Wind on Fire Spread Rate
}

\author{
Carlos G. Rossa * (iD) and Paulo M. Fernandes \\ Centre for the Research and Technology of Agro-environmental and Biological Sciences (CITAB), \\ University of Trás-os-Montes e Alto Douro (UTAD), Quinta de Prados, Apartado 1013, 5001-801 Vila Real, \\ Portugal; pfern@utad.pt \\ * Correspondence: carlos.g.rossa@gmail.com
}

Received: 8 August 2018; Accepted: 28 August 2018; Published: 1 September 2018

\begin{abstract}
Predicting wind-driven rate of fire spread (RoS) has been the aim of many studies. Still, a field-tested model for general use, regardless of vegetation type, is currently lacking. We develop an empirical model for wind-aided RoS from laboratory fires $(n=216)$, assuming that it depends mainly on fire-released energy and on the extension of flame over the fuel bed in still air, and that it can be obtained by multiplying RoS in no-wind and no-slope conditions by a factor quantifying the wind effect. Testing against independent laboratory and field data $(n=461)$ shows good agreement between observations and predictions. Our results suggest that the fuel bed density effect detected by other work may be a surrogate for the amount of fuel involved in combustion, which depends on fuel load. Because RoS under windless conditions is unaffected by fuel load, the involved mechanisms differ from wind-aided propagation. Compared to shallow fuel beds, the wind effect is usually modest in deep vegetation, because tall fuel complexes are dominated by live fuels (high moisture content) and flames extend less above the vegetation when fuel moisture is high. The present work warrants further inspection in a broader range of field conditions.
\end{abstract}

Keywords: empirical modelling; combustion rate; fuel bed height; flame height

\section{Introduction}

The prediction of wind-driven fire spread rate $\left(R_{\mathrm{U}}\right)$ has been the purpose of many modelling efforts since the inception of fire behavior research $[1,2]$. The dramatic effect of heading wind on fire propagation is evident. As the wind speed $(U)$ increases, the flame is tilted towards unburned fuel and heat transfer is enhanced, thus increasing spread rate $(R)$. Positive slope terrain has a similar effect to heading wind, in the sense that it also brings the flame closer to the fuel, causing an increase in $R$. However, when the distance travelled is sizably larger than distances between landscape undulations, $R$ is satisfactorily equated to that of a fire spreading across a corresponding expanse of flat ground [3]. The distance travelled by large fires is then mainly a function of $U$, which confirms the importance of accurate and user-friendly prediction of $R_{\mathrm{U}}$ for fire management purposes.

Physically based formulations of fire spread (e.g., [4]) are credited to be more generally valid across different fuel and weather conditions [5] than empirical ones. However, although they are usually very complex, no such model has been able to provide reliable predictions for a general free-spreading field fire so far. Hence, for the foreseeable future, fire behavior modelling assistance to decision-making in fire management is expected to continue relying on the use of empirically based prediction systems [6]. Empirical models are usually derived from 'experimental' fires-i.e., those of which the only purpose is research (e.g., [7]). The following steps are typically undertaken in empirical approaches [8]: fuel and terrain descriptions (e.g., vegetation characteristics, slope); atmospheric-related environment measurement (e.g., $U$, air temperature, relative humidity, fine fuel moisture content); fire measurement 
(e.g., $R$, flame geometry); and statistical analysis to develop relationships to predict fire behavior characteristics. Although empirical formulations can be derived from either laboratory or field fires, the latter option is frequently preferred [9], based on the premise that field experiments under natural conditions are a better proxy to real wildfires.

Several review studies offer insight into the most relevant empirical fire-spread models developed to date $[8,10,11]$. Most of them are fuel-type specific and are available for a range of relevant natural fuel complexes, pertaining to forests [12-16], shrublands [17-20], and grasslands [7,21,22]. The required weather, fuel moisture, and fuel structure input variables can be quite diverse [11], though some are common in most formulations, namely $U$ measured at heights of either $\sim 2 \mathrm{~m}\left(U_{2}\right)$ or $10 \mathrm{~m}\left(U_{10}\right)$, dead fine fuel moisture content $\left(M_{\mathrm{d}}\right)$, and fuel bed height $(h)$. The effect of wind speed is ordinarily built-in as a power function $U^{b}$, although some studies use exponential or linear functions [8].

A notable case of a quasi-empirical formulation [8] is the Rothermel model [23]. Primarily developed from laboratory experiments in homogeneous dead fuels, it has gained worldwide acceptance and continued to be extensively used to assist both research and operational activities. Despite its empirical nature, the Rothermel model uses several variables describing the mechanisms of fire spread and obtains $R$, of either wind or slope-driven fires, by computing $R$ in no-wind and no-slope conditions $\left(R_{0}\right)$ and using adimensional coefficients to account for the effects of wind and slope. Although it is used to predict $R$ in all types of vegetation, it is mathematically extended to account for the damping effect of live fuels. A field-tested empirical $R_{\mathrm{U}}$ model for general use, regardless of vegetation type and structure, is currently lacking.

In this work, we developed a simple empirical model for estimating the effect of wind speed on $R$. We hypothesized that the influence of the main propagation mechanisms can be indirectly described by a single formulation and a common set of variables, independently of vegetation type. The model was fitted to laboratory experiments data and then tested against independent laboratory and field fires. For the convenience of the reader, a list of the variables used throughout this work (including their symbols, units and definitions) is given at the end of the article.

\section{Methods}

\subsection{Overview}

Our modelling effort is based on the assumption that $R_{\mathrm{U}}$ can be obtained by multiplying $R_{0}$ by an adimensional factor accounting for the effect of wind $\left(R_{\mathrm{U}}^{\prime}\right.$, Equation (1)), similar to the Rothermel approach [23]. We seek to model $R_{\mathrm{U}}^{\prime}$ to obtain $R_{\mathrm{U}}$ by using measured or predicted $R_{0}\left(R_{0}\right.$ model developed elsewhere). The 'Methods' section is organized as follows: firstly, we describe the laboratory tests on which the modelling work was based upon; we then present the rationale to derive the model's functional form, followed by the statistical methods to obtain the coefficients fitted; and finally we refer to the process of model testing against independent laboratory and field data.

\subsection{Development Data}

We used data from 108 laboratory experiments, of which 78 were retrieved from previous studies [24,25]. The full dataset is supplied in Table A1 in Appendix A. Each experiment was composed of two consecutive burns (totaling 216 fires) in identical fuel beds (e.g., [26]), one measuring $R_{0}$ and the other measuring $R_{\mathrm{U}}$. The effect of wind, quantified by $R_{\mathrm{U}}^{\prime}$, was then obtained:

$$
R_{\mathrm{U}}^{\prime}=\frac{R_{\mathrm{U}}}{R_{0}}
$$

Four species were used (Acacia mangium Willd; Pinus pinaster Ait.; Pinus resinosa Sol. ex Ait.; Eucalyptus globulus Labill.) to build three differently arranged fuel beds, defined by fuel particle orientation: horizontal (litter, slash); horizontal-vertical (litter over-layered by vertical quasi-live tree twigs); and vertical (dead tree twigs). 
All fuel beds were at least $1 \mathrm{~m}$ long and 1 to $1.2 \mathrm{~m}$ wide; the wind-driven experiments in [24] were carried out in larger fuel beds of variable sizes. Additional experiments were carried out to supplement the experimental variable ranges available beforehand, in regards to the distribution of $U$ and $h$ data. Thus, we used $U=4 \mathrm{~km} \cdot \mathrm{h}^{-1}$ and built deep litter, and about 0.25 - and 0.40 -m-tall vertical twig beds. Fuel load $(w)$ and fuel bed density $\left(\rho_{\mathrm{b}}\right)$ exclude woody fuels, i.e., calculations were based solely on leaf litter and elevated foliage based on the assumption that thicker elements contribute less to the fire front advance. With a few exceptions, air temperature $\left(T_{\mathrm{a}}\right)$ and relative humidity $(R H)$ were measured just before the burns, which were line-ignited after fuel sampling to assess fuel bed foliar moisture content $(M)$ by oven-drying or using a moisture analyzer [27]. $R_{0}$ and $R_{U}$ were determined by timing the base of the flame over a given length, and flame length $\left(L_{\mathrm{f}}\right.$, measured from the base of the fuel bed) and flame angle ( $A_{\mathrm{f}}$, measured from the unburned fuel), except for those in [24], were visually assessed. In $R_{0}$ tests, flames are approximately vertical and the flame height $\left(H_{\mathrm{f}}\right)$ equals $L_{\mathrm{f}}$.

\subsection{Empirical Model}

The present formulation attempts to incorporate some variables that we assumed to indirectly account for some of the main mechanisms driving the effect of wind on fire spread. Nevertheless, our approach is empirical and does not aim for a sound physical description of fire behavior. Instead, our goal was to develop a set of equations grounded on the principle that they 'work' to obtain reasonable $R_{\mathrm{U}}$ estimates.

Wind tilts the head fire flame towards the unburned fuel, enhancing heat transfer and thus increasing $R$. This model builds on the assumption that the effect of wind on $R$ is mainly a function of two measures of fire spread under still air conditions: (i) the energy released by combustion, and (ii) flame extension over the fuel bed. The flame is more difficult to be tilted by wind when the vertical momentum of the combustion convection column is high. We assumed that the momentum of the hot gases is proportional to the rate of fuel addition to the combustion reaction $\left(\dot{w}_{0}\right)$, which, for a fire spreading in still air on level ground, can be obtained in units of $\mathrm{kg} \cdot \mathrm{s}^{-1} \cdot \mathrm{m}^{-1}$ as:

$$
\dot{w}_{0}=R_{0} w
$$

Equation (2) assumes total $w$ consumption, which is reasonable since only foliar fuels are considered to determine $w$. We can distinguish the flame that develops: (i) within the fuel bed and transfers heat to the unburned fuel as a mixture of convection and radiation [28]; and (ii) above the fuel bed, contacting the unburned fuel and transferring heat mainly by radiation, and by convection if wind is present. In the absence of wind, the flame is roughly vertical and the view factor between the flame and the fuel bed is low [29]. Consequently, in the particular case of windless fire spread, most of the heat leading to ignition comes from the combustion zone inside the fuel bed [30,31]. Hence, the higher the flames extend above the fuel bed, the higher the potential for enhanced heat transfer if wind is added, increasing $R_{\mathrm{U}}$. We quantified flame extension above the fuel bed in $R_{0}$ conditions by the ratio of $h$ to $H_{\mathrm{f}}[25]$, i.e., $\left(h / H_{\mathrm{f}}\right)_{0}$.

Finally, following the previously discussed rationale and assuming that $U$, $\dot{w}_{0}$, and $\left(h / H_{\mathrm{f}}\right)_{0}$ can account for most of the potential wind effect on a fire spreading in still air, we obtained the model as:

$$
R_{\mathrm{U}}^{\prime}=1+a U^{b} \dot{w}_{0}^{\mathrm{c}}\left(\frac{h}{H_{\mathrm{f}}}\right)_{0}^{d}
$$

where $a, b, c$, and $d$ are the coefficients fitted.

\subsection{Model Fitting}

Parameters in Equation (3) were determined by least squares fitting to the log-transformed form of $\left(R_{\mathrm{U}}^{\prime}-1\right)$ and the bias inherent to back-transformation was corrected [32]. Because $H_{\mathrm{f}}$ was not assessed 
in all $R_{0}$ trials, we used those measured to fit $\left(h / H_{\mathrm{f}}\right)_{0}$ as a function of $M$ [25] and the corresponding relationship between $\left(h / H_{\mathrm{f}}\right)_{0}$ and $M$ was written as:

$$
\left(\frac{h}{H_{\mathrm{f}}}\right)_{0}^{d}=a+b M
$$

Equation (4) was then used to obtain $\left(h / H_{\mathrm{f}}\right)_{0}$ estimates for all $R_{0}$ tests. In fuel beds composed of dead and live fuels, $M$ was given by weighted foliar fuel moisture $\left(M_{\mathrm{W}}\right)$ :

$$
M_{\mathrm{w}}=f_{\mathrm{d}} M_{\mathrm{d}}+\left(1-f_{\mathrm{d}}\right) M_{\mathrm{l}}
$$

where $f_{\mathrm{d}}$ is the mass fraction of dead foliar fuels and $M_{\mathrm{l}}$ is live fine fuel moisture content. $f_{\mathrm{d}}$ was calculated as:

$$
f_{\mathrm{d}}=\frac{w_{\mathrm{d}}}{w_{\mathrm{l}}+w_{\mathrm{d}}}
$$

where $w_{\mathrm{d}}$ and $w_{1}$ are dead and live foliar fuel load, respectively. The influence of fuel bed arrangement on $\left(h / H_{\mathrm{f}}\right)_{0}$ and $R_{\mathrm{U}}^{\prime}$ was examined as a categorical variable.

\subsection{Laboratory Testing}

The model was tested using independent data (Figure 1) from wind-driven laboratory fires $(n=301)$ carried out by Catchpole et al. [33]. Two fuel arrangements were used: horizontal (Pinus ponderosa Douglas ex C.Lawson needles, Populus tranulos regular and coarse excelsior), and vertical ( $P$. ponderosa sticks arrays). Fuel beds were line-ignited and were 1-m wide and 5-8 $\mathrm{m}$ long. Because $R_{0}$ measurements were not available in [33], $R_{0}$ estimates were obtained using the model in [34], applicable to a general fuel bed, and $R_{0}$ was computed from:

$$
R_{0}=0.1557 M^{-0.7734} h^{0.944} \ln \left(0.8173 S_{\mathrm{m}}\right)
$$

where $S_{\mathrm{m}}$ is the fuel particles surface area-to-mass ratio that can be obtained from:

$$
S_{\mathrm{m}}=\frac{S_{\mathrm{v}}}{\rho_{\mathrm{p}}}
$$

where $S_{\mathrm{v}}$ and $\rho_{\mathrm{p}}$ are fuel particle surface area-to-volume ratio and fuel particle density, respectively. Equation (7) was developed and validated in [34]: fitting was based in a dataset of 225 laboratory $R_{0}$ experiments and validation resorted to a comprehensive group of 106 field fires in very diverse fuel complexes.

In fuel complexes composed of several particle diameter classes, the present model considers foliar fuels $(<\sim 2 \mathrm{~mm}$ ) only, assuming that thicker elements burn slower and contribute less to support head fire spread. However, the vertical sticks used by Catchpole et al. [33] were $6 \mathrm{~mm}$ thick. In this case, no thinner elements were present and the fire front advance must be determined by stick combustion. Using Equations (2)-(4), $R_{\mathrm{U}}^{\prime}$ was computed. Finally, predicted $R_{\mathrm{U}}$ was obtained from:

$$
R_{\mathrm{U}}=f_{\mathrm{il}} R_{\mathrm{U}}^{\prime} R_{0}
$$

where $f_{\mathrm{il}}$ is the ignition line length $(I L)$ factor, which quantifies the growth of $R$ due to increasing IL [20], caused by heat transfer along the fire flanks that concentrates in the head fire [24], accelerating it. Because $f_{\text {il }}$ was not available beforehand, it had to be estimated. Cheney and Gould (1995) [35] made $f_{\text {il }}$ a function of $U$ intervals, but here, we considered a single $f_{\text {il }}$ value. In [33], the fuel bed width was the same as in our model development tests, but strips of metal sheeting were placed along each side of the fuel tray to mimic a wider fire front by preventing indrafts into the combustion zone and by reflecting some of the radiation. In the absence of a method to suitably compute $f_{\text {il }}$ for this situation, 
we plotted observed vs. predicted $R_{\mathrm{U}}$ values using our model and adjusted $f_{\text {il }}$ to minimize the absolute mean bias error (MBE).

We predicted $R_{\mathrm{U}}$ with the Rothermel model [23], for comparison, using the fire spread equations in SI units [36]. Fuel heat content, total mineral content, and effective mineral content were assumed constant and equal to $18,608 \mathrm{~kJ} \cdot \mathrm{kg}^{-1}, 0.0555$, and 0.01 , respectively [23]. Moisture of extinction was set at 30\% [33]. The remaining model inputs are $w, h, S_{\mathrm{v}}, \rho_{\mathrm{p}}, M$, and $U$. Because the Rothermel model was developed mostly from laboratory tests in the same experimental apparatus used by Catchpole et al. [33], correction of the predicted $R_{U}$ for the IL effect, as in Equation (9), was unneeded.

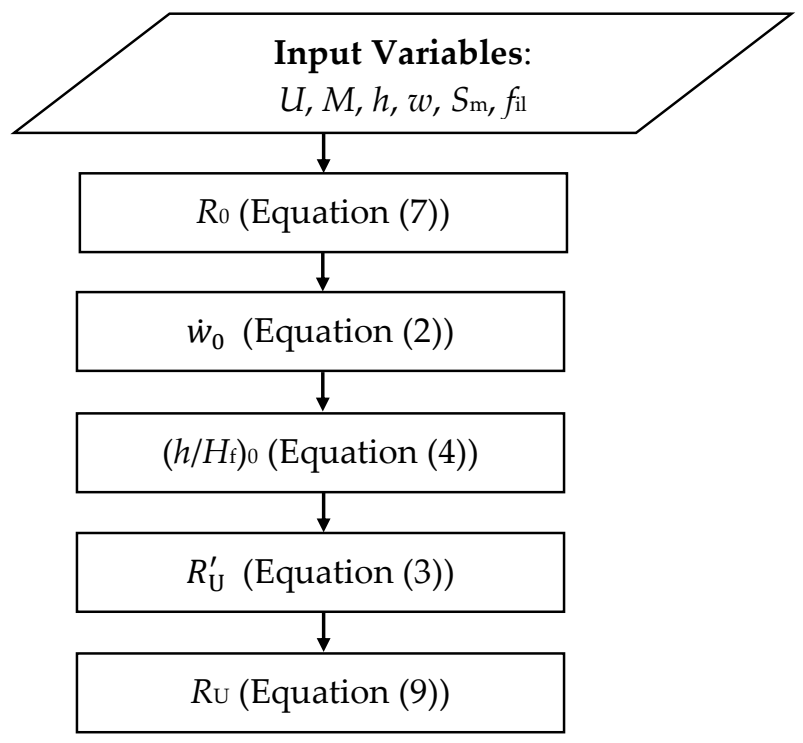

Figure 1. Flow diagram describing the $R_{\mathrm{U}}$ model. Predicted $R_{\mathrm{U}}$ were first computed using $f_{\mathrm{il}}=1$ and afterwards $f_{\text {il }}$ was calibrated to minimize MBE between observed and predicted $R_{\mathrm{U}}$ values. In vegetation composed of dead and live fuels, $M$ was calculated using Equations (5) and (6). $S_{\mathrm{m}}$ was determined using Equation (8); when $S_{\mathrm{v}}$ and $\rho_{\mathrm{p}}$ values were not available, typical $S_{\mathrm{m}}$ values of 7.7 and $38.0 \mathrm{~m}^{2} \cdot \mathrm{kg}^{-1}$ were considered, respectively, for foliage-based and grassland fuel complexes. Variables and abbreviations used are: $U$, wind speed (measured at $\sim 2 \mathrm{~m}$ in field fires); $M$, fuel complex foliar moisture content; $h$, fuel bed height; $w$, fuel load; $S_{\mathrm{m}}$, surface area-to-mass ratio; $f_{\mathrm{il}}$, ignition line length factor; $R_{0}$, basic fire spread rate (i.e., no-wind and no-slope); $\dot{w}_{0}$, rate of fuel addition to the combustion reaction; $H_{\mathrm{f}}$, flame height (measured from the base of the fuel bed); $R_{\mathrm{U}}^{\prime}$, adimensional wind-driven fire spread rate; $R_{\mathrm{U}}$, wind-driven fire spread rate; $S_{\mathrm{v}}$, surface area-to-volume ratio; $\rho_{\mathrm{p}}$, fuel particle density; MBE, mean bias error.

\subsection{Field Testing}

We tested the model against field fire data $(n=160)$ from the literature, in three generic vegetation types [37]: shrubland, forest, and grassland. Our purpose was two-fold: (i) to test the model functional form against real-world data, and (ii) to test it well beyond the development data ranges for a more robust statement of its ability to indirectly account for the main mechanisms involved in wind-driven fire propagation.

Variation of $U$ with height is usually low in the laboratory. However, $U$ increases substantially with height in the open [38] and models require the input of $U$ measured at standard heights. In the available field datasets, $U$ was measured at a $\sim 2 \mathrm{~m}$ height. We assumed that the effect of our measured $U$ on laboratory flames is roughly comparable to the $\sim 2 \mathrm{~m}$ height wind effect on the flames of field fires.

We used shrublands fires $(n=44)$ compiled by Anderson et al. [20] from [18,39-41], and restricted $I L$ to $20-60 \mathrm{~m}$, to minimize differences in $R_{\mathrm{U}}$ caused by $I L$ variation. We chose this $I L$ interval because it maximized the number of available fires within a limited $I L$ range. Because it was not practical to 
obtain $S_{\mathrm{m}}$ values for such a wide range of fuel species, we used a simplified version of Equation (7) to estimate $R_{0}$. This simplified $R_{0}$ model is equivalent to using Equation (7) with $S_{\mathrm{m}}=7.7 \mathrm{~m}^{2} \cdot \mathrm{kg}^{-1}$ and was shown to yield good results for a wide range of foliage-dominated fuel complexes [34]. Because $w$ accounts for foliage fuels only and shrubs can have a significant amount of fine woody fuels thicker than foliage, the fine fuel load (FFL) of elements $<2.5 \mathrm{~mm}$ was used as a surrogate for $w$ and was estimated as 0.583 for Total FFL ${ }^{0.854}$ [42]. Whenever this estimate exceeded Total FFL, we retained the latter value instead. Variable $\left(h / H_{\mathrm{f}}\right)_{0}$ was calculated with Equation (4).

Fires in Pinus pinaster forest understory $(n=46)$ and in pasture grasslands $(n=70)$ were retrieved from [15] and [43,44], respectively. Because some of the fires in forest were carried out in tilted terrain, reported $R$ was corrected for expected $R$ in flat ground, based on the effect of slope determined by Fernandes et al. (2009) [15]. The simplified version of Equation (7) [34] was also deemed a good approach to estimate $R_{0}$ in $P$. pinaster forest. For grasslands, we assumed $S_{\mathrm{m}}=38.0 \mathrm{~m}^{2} \cdot \mathrm{kg}^{-1}$, computed from $S_{\mathrm{v}}$ and $\rho_{\mathrm{p}}$ values for mixed grass [45]. Again, we estimated $\left(h / H_{\mathrm{f}}\right)_{0}$ from Equation (4), but because $H_{\mathrm{f}}$ was available both for forest and grassland, we fitted the functional form of Equation (4) to obtain fuel-specific $h / H_{\mathrm{f}}$ models for these two vegetation types. We then assessed how our laboratory-derived $\left(h / H_{\mathrm{f}}\right)_{0}$ model was compared with the fuel-specific $h / H_{\mathrm{f}}$ relationships by plotting the three functions. The purpose of this comparison was two-fold: (i) to appraise the suitability of Equation (4) for different vegetation types; and (ii) to examine whether the $\left(h / H_{\mathrm{f}}\right)_{0}$ ratio is constant when fire spread is wind-assisted, as suggested by Rossa and Fernandes [25], meaning that $H_{\mathrm{f}}$ remains roughly constant even when flame length increases as a result of wind. It is important to recall that $H_{\mathrm{f}}$ was always measured from the base of the fuel bed, and to notice that the $h / H_{\mathrm{f}}$ ratio of field data was restricted to head fires in approximately flat terrain; our $h / H_{\mathrm{f}}$ model should not be considered for backing fires.

We adjusted $f_{\mathrm{il}}$ to predict $R_{\mathrm{U}}$ of field fires, following the same process as in the validation with independent laboratory trials. Figure 1 summarizes all steps necessary to obtain $R_{\mathrm{U}}$ predictions for the independent validation fires. Although Equation (9) is thought to be applicable to wind-driven field fires of variable IL spreading in flat terrain over any fuel complex, $f_{i l}$ is presumed to be fuel-specific. However, we expect that beforehand calibration of $f_{\mathrm{il}}$ for some generic vegetation types will allow obtaining reasonable $R_{\mathrm{U}}$ estimates for most typical real-world fire propagation situations.

We obtained exploratory functions to estimate it, so that future validation efforts of Equation (9) do not require a priori $f_{\mathrm{il}}$ adjustment. To do so, firstly, we used results from the literature to derive correction factors to convert the considered field fires $R_{\mathrm{U}}$ to potential quasi-steady $R_{\mathrm{U}}$, which we admitted to be nearly achieved for $I L=50 \mathrm{~m}[20,35]$. The correction factor to obtain quasi-steady $R_{\mathrm{U}}$ for shrubland fires was computed as in [20], using $I L=35 \mathrm{~m}$ (experimental mean) as an input. The ratio between $R_{\mathrm{U}}$ of forest field tests $\left(I L=10 \mathrm{~m}\right.$ ) and arguably quasi-steady $R_{\mathrm{U}}$ of wildfires in the same vegetation type was evaluated by Fernandes [46]. Cheney and Gould (1995) [35] provide an empirical function to obtain grassland fires quasi-steady $R_{\mathrm{U}}$ for several $U$ intervals. We computed the correction factor for each $U$ interval using $I L=33 \mathrm{~m}$, and then took the mean value. We then estimated $f_{\text {il }}$ to upscale our laboratory tests $R_{\mathrm{U}}$ to potential quasi-steady $R_{\mathrm{U}}$ by multiplying the correction factors by the adjusted $f_{\text {il }}$ to predict $R_{\mathrm{U}}$ of field fires. Finally, for each vegetation type and based on well-established evidence on the expected evolution of $f_{\text {il }}$ with $I L$, and knowing that for $I L=1 \mathrm{~m}$, we must obtain $f_{\mathrm{il}}=1$, we fitted the functional form $f_{\mathrm{il}}=1+a \ln (I L)$.

We also predicted $R_{\mathrm{U}}$ using fuel-specific models for shrubland [20], forest [15], and grassland [44] for comparison. Evaluation of predictions (laboratory and field independent data) resorted to root mean square error (RMSE), mean absolute error (MAE), and mean absolute percentage error (MAPE), besides MBE [47]. Residuals were checked for normality. 


\section{Results}

\subsection{Development Data and Model Fitting}

Development data included diverse fuel species, arrangements and structures (Table 1). Because some of the tests approached the structure of natural mixed live and dead vegetation, the $M$ interval was uncommonly wide (5-162\%). U varied in the $3.6-16.2 \mathrm{~km} \cdot \mathrm{h}^{-1}$ range and; as a result, $R_{\mathrm{U}}^{\prime}$ varied between 1.1 and 24.8 .

The linear fit for $\left(h / H_{\mathrm{f}}\right)_{0}$ (Equation (4)) yielded $R^{2}=0.692$ (Table 2) and predictions agreed well with observations (Figure $2 \mathrm{a})$. Observed $\left(h / H_{\mathrm{f}}\right)_{0}$ was always below unity (theoretical maximum value) which agrees with empirical evidence from the laboratory and field that, in sustained fire spread, $H_{\mathrm{f}}$ will always extend above $h$. In the case of multilayer fuel complexes, where some of the elevated layers do not participate in combustion, they should not be accounted for to assess $h$. Fuel bed arrangement had a significant effect on $\left(h / H_{\mathrm{f}}\right)_{0}$, with the horizontal beds differing from the other two arrangements, and allowed for an increase in $R^{2}(0.778)$. This suggests that other variables, namely structural descriptors, add to the explanation of $\left(h / H_{\mathrm{f}}\right)_{0}$, which was previously noticed [25]. Nevertheless, we found that predictions using a single independent variable were satisfactory, and for the sake of parsimony, only $M$ was retained in the model. Variable $\left(h / H_{\mathrm{f}}\right)_{0}$ estimates, along with the remaining necessary variables to predict $R_{\mathrm{U}}^{\prime}$ (Equation (3)), explained $83.3 \%$ of its variability and fuel bed arrangement was not significant. There was a tendency for increasingly higher scatters between observed and predicted values as $R_{U}^{\prime}$ increased, which was expected, given the unstable nature of fire spread under rising winds, but the good fit is manifest (Figure 2b). In both Equations (3) and (4) all variables were significant at $p<0.0001$.
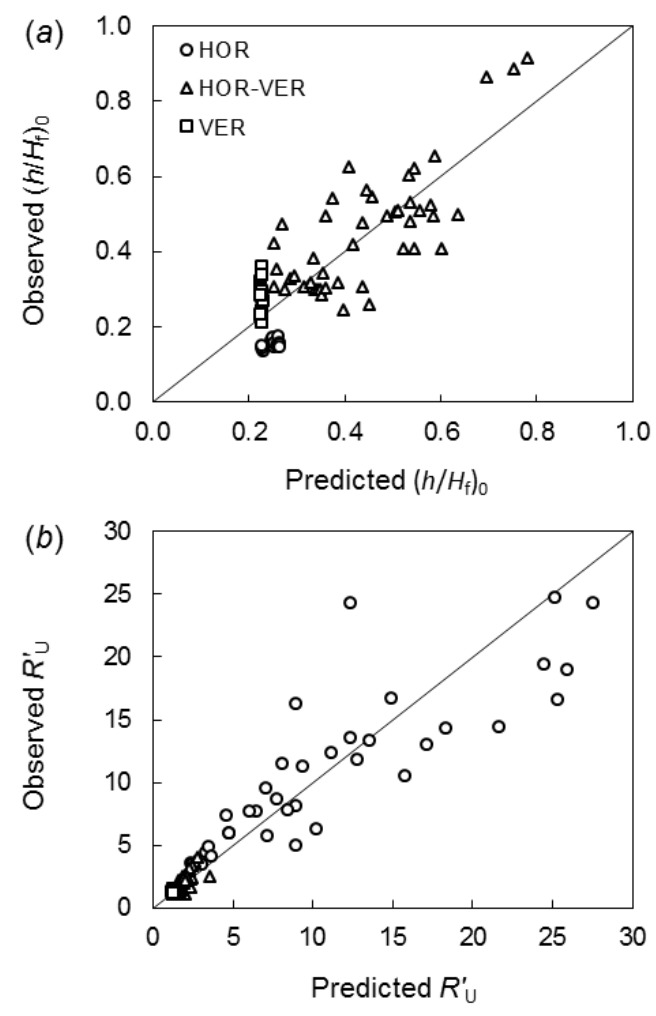

Figure 2. Observed vs. predicted: (a) ratio of fuel bed height $(h)$ to flame height $\left(H_{\mathrm{f}}\right.$, measured from the base of the fuel bed) in windless conditions for the development data (Table 1); and (b) adimensional wind-driven fire spread rate $\left(R_{\mathrm{U}}^{\prime}\right)$ for the development data. Fuel bed arrangement: HOR-horizontal; HOR-VER - horizontal and vertical; VER - vertical. Fitted coefficients for Equations (3) and (4) are given in Table 2. 
Table 1. Summary of the development data.

\begin{tabular}{|c|c|c|c|c|c|c|c|c|c|c|}
\hline Fuel Arrangement & Fuel Bed & $n$ & $w\left(\mathrm{~kg} \cdot \mathrm{m}^{-2}\right)$ & $h(\mathrm{~m})$ & $\rho_{\mathrm{b}}\left(\mathrm{kg} \cdot \mathrm{m}^{-3}\right)$ & $M(\%)$ & $U\left(\mathbf{k m} \cdot \mathrm{h}^{-1}\right)$ & $R_{0}\left(\mathrm{~m} \cdot \mathrm{s}^{-1}\right)$ & $R_{\mathrm{U}}\left(\mathrm{m} \cdot \mathrm{s}^{-1}\right)$ & $R_{\mathrm{U}}^{\prime}$ \\
\hline \multirow{4}{*}{ Horizontal } & Pinus pinaster Ait. needles [24] & 18 & $0.60-0.80$ & $0.054-0.112$ & 7.1-11.1 & $11.2-16.7$ & $3.6-16.2$ & $0.0022-0.0035$ & $0.0093-0.0581$ & $3.5-16.7$ \\
\hline & Eucalyptus globulus Labill. slash [24] & 15 & $0.45-0.59$ & $0.075-0.102$ & $5.8-5.9$ & $5.2-13.8$ & $3.6-16.2$ & $0.0020-0.0054$ & $0.0129-0.1300$ & $3.5-24.8$ \\
\hline & P. pinaster needles & 12 & $1.46-1.85$ & $0.090-0.148$ & $12.1-16.3$ & $18.1-23.1$ & 4.0 & $0.0031-0.0042$ & $0.0043-0.0061$ & $1.3-1.6$ \\
\hline & Acacia mangium Willd. leaves & 3 & $0.53-0.57$ & $0.042-0.054$ & $10.6-12.7$ & $12.7-14.1$ & 8.0 & $0.0018-0.0028$ & $0.0138-0.0184$ & $5.0-10.5$ \\
\hline \multirow[t]{3}{*}{ Horizontal-vertical } & $\begin{array}{l}\text { P. resinosa Sol. ex Ait. needles and vertical quasi-live } \\
\text { P. pinaster branches [25] }\end{array}$ & 12 & $1.27-1.64$ & $0.301-0.371$ & $3.9-4.7$ & $64.5-162.4$ & 8.0 & $0.0021-0.0047$ & $0.0024-0.0090$ & $1.1-2.6$ \\
\hline & $\begin{array}{l}\text { P. pinaster needles and vertical quasi-live } \\
\text { P. pinaster branches [25] }\end{array}$ & 21 & $1.16-1.89$ & $0.312-0.374$ & $3.6-5.7$ & $36.9-123.5$ & 8.0 & $0.0019-0.0051$ & $0.0043-0.0111$ & $1.7-4.1$ \\
\hline & $\begin{array}{l}\text { E. globulus leaves and vertical quasi-live } \\
\text { E. globulus branches [25] }\end{array}$ & 12 & $0.66-1.62$ & $0.332-0.382$ & $2.0-4.3$ & $19.6-71.8$ & 8.0 & $0.0033-0.0109$ & $0.0081-0.0214$ & $1.1-2.6$ \\
\hline Vertical & E. globulus branches & 15 & $0.63-0.89$ & $0.244-0.426$ & $1.7-3.3$ & $12.1-13.5$ & 4.0 & $0.0111-0.0183$ & $0.0138-0.0261$ & $1.1-1.5$ \\
\hline
\end{tabular}

Variables used are: $w$, foliar fuel load; $h$, fuel bed height; $\rho_{\mathrm{b}}$, fuel bed density; $M$, fuel bed foliar moisture content; $U$, wind speed; $R_{0}$, basic fire spread rate; $R_{\mathrm{U}}$, wind-driven fire spread rate

$R_{\mathrm{U}}^{\prime}$, adimensional wind-driven fire spread rate.

Table 2. Fitted coefficients of models.

\begin{tabular}{|c|c|c|c|c|c|c|}
\hline Model & $n$ & $a$ & $b$ & $c$ & $d$ & $R^{2}$ \\
\hline Equation (4) $\mathrm{A}$ & 75 & $0.1779(0.1414-0.2143)$ & $3.713 \times 10^{-3}\left(3.136 \times 10^{-3}-4.291 \times 10^{-3}\right)$ & - & - & 0.692 \\
\hline Equation $(3)^{B}$ & 108 & $2.143 \times 10^{-5}\left(0.992 \times 10^{-5}-4.629 \times 10^{-5}\right)$ & $1.710(1.453-1.967)$ & $-1.169(-1.313--1.024)$ & $-1.166(-1.433--0.898)$ & 0.833 \\
\hline
\end{tabular}

$95 \%$ confidence intervals for fitted coefficients $a, b, c$ and $d$ are shown in parenthesis; $R^{2}$, coefficient of determination. ${ }^{\mathrm{A}}$ Fitted to the sub-group of tests reported in Table A1 carried out under windless conditions where flame height was measured. ${ }^{\mathrm{B}}$ Fitted to the complete dataset reported in Table A1. 


\subsection{Laboratory Testing}

In the independent laboratory dataset (Table 3), $U$ and $w$ varied in the $1.6-11.3 \mathrm{~km} \cdot \mathrm{h}^{-1}$ and $0.1-3.6 \mathrm{~kg} \cdot \mathrm{m}^{-2}$ ranges, respectively. Because only dead fuels were included, the $M$-range (3-28\%) was narrower than that in the development dataset, but the other variables varied widely. We obtained $f_{\text {il }}=2.4$, which yielded the MBE of $0.0001 \mathrm{~m} \cdot \mathrm{s}^{-1}$. The model produced a reasonable fit with MAPE $=36.9 \%$. Although the maximum $R_{\mathrm{U}}$ in the development dataset was $0.13 \mathrm{~m} \cdot \mathrm{s}^{-1}$, the model yielded consistent results (Figure 3a) up to twice that value $\left(0.25 \mathrm{~m} \cdot \mathrm{s}^{-1}\right)$. The Rothermel model fell behind the results of our formulation: the MAPE was substantially higher (48.7\%), and despite an overall tendency for under-prediction $(\mathrm{MBE}<0)$, we can observe some extreme over-predictions for upper $R_{\mathrm{U}}$ observations (Figure $3 \mathrm{~b}$ ).
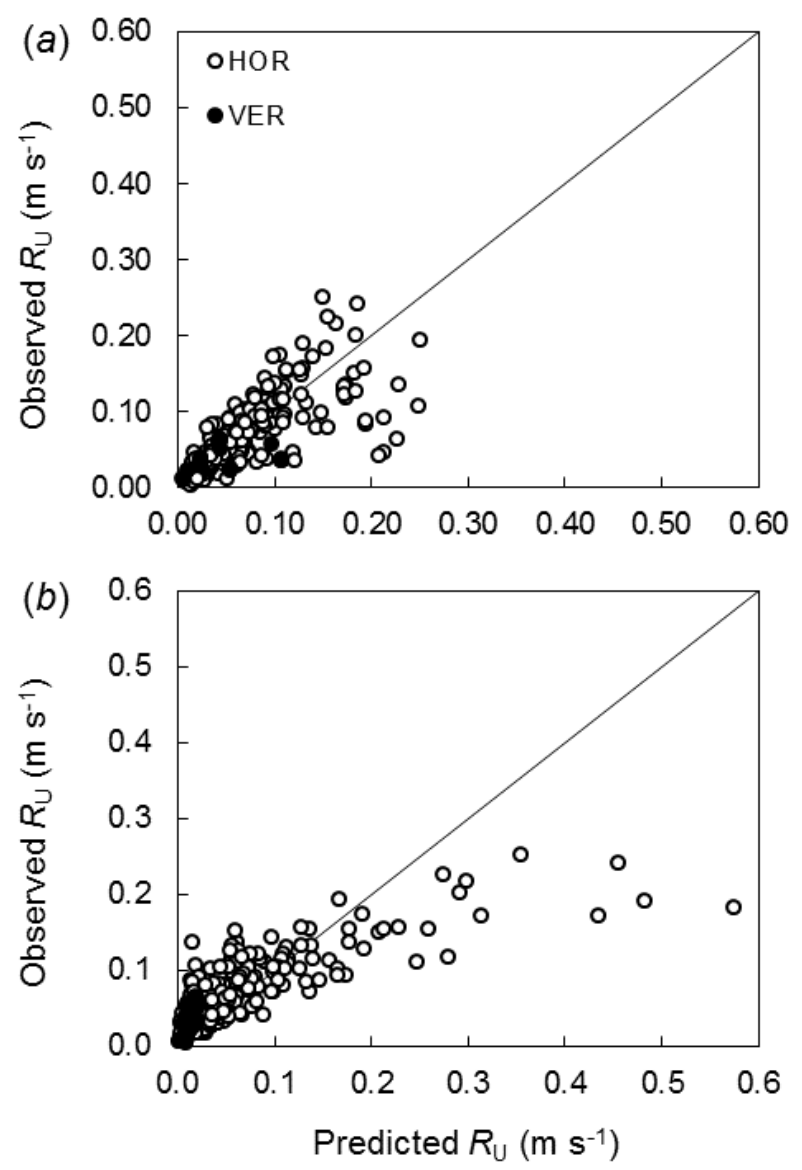

Figure 3. Observed vs. predicted wind-driven fire spread rate $\left(R_{\mathrm{U}}\right)$ for the laboratory validation data (Table 3) using: (a) the present model; and (b) the Rothermel model [23]. Fuel bed arrangement: HOR-horizontal; VER — vertical. Model evaluation metrics are given in Table 5.

\subsection{Field Testing}

Most field data variables substantially exceeded those used for development, e.g., the maximum $U$ was $26.2 \mathrm{~km} \cdot \mathrm{h}^{-1} ; h$ and $R_{\mathrm{U}}$ attained values over 4 and 17 times greater, respectively (Table 4 ). We obtained $f_{\text {il }}$ of $11.8,4.7$, and 3.8, respectively, for validation fires in shrubland, forest, and grassland, yielding MBEs of $-0.0002 \mathrm{~m} \cdot \mathrm{s}^{-1},-0.00003 \mathrm{~m} \cdot \mathrm{s}^{-1}$, and $0.0002 \mathrm{~m} \cdot \mathrm{s}^{-1}$, respectively (Table 5). Overall, the present model (Figure 4) performed similarly to fuel-specific formulations. For shrubland, the MAPE of $75.1 \%$ was very close to that obtained using the model of Anderson et al. (72.7\%) [20]. For forest, all deviation measures, except MAPE ( 54.9 vs. $45.0 \%$ ), were very similar. In grassland fires, our formulation outperformed the fuel-specific model in all evaluation metrics. All residuals were normally or approximately normally distributed. 
Table 3. Summary of the laboratory validation data retrieved from [33].

\begin{tabular}{|c|c|c|c|c|c|c|c|c|c|c|}
\hline $\begin{array}{c}\text { Fuel } \\
\text { Arrangement }\end{array}$ & Fuel Bed & $n$ & $w\left(\mathrm{~kg} \cdot \mathrm{m}^{-2}\right)$ & $h(\mathrm{~m})$ & $\rho_{\mathrm{b}}\left(\mathrm{kg} \cdot \mathrm{m}^{-3}\right)$ & $S_{\mathrm{v}}\left(\mathrm{m}^{-1}\right)$ & $\rho_{\mathrm{p}}\left(\mathrm{kg} \cdot \mathrm{m}^{-3}\right)$ & $M(\%)$ & $U\left(\mathbf{k m} \cdot \mathrm{h}^{-1}\right)$ & $R_{\mathrm{U}}\left(\mathrm{m} \cdot \mathrm{s}^{-1}\right)$ \\
\hline \multirow{3}{*}{ Horizontal } & Pinus ponderosa Douglas ex C.Lawson needles & 77 & $0.25-3.64$ & $0.013-0.076$ & $10.2-47.9$ & 5710 & 510 & $2.9-28.2$ & $1.6-11.3$ & $0.004-0.093$ \\
\hline & Populus tranulos regular excelsior & 88 & $0.15-2.43$ & $0.051-0.305$ & $1.6-15.9$ & 7596 & 398 & $2.7-27.0$ & $1.6-9.6$ & $0.018-0.136$ \\
\hline & P. tranulos coarse excelsior & 118 & $0.10-1.81$ & $0.025-0.152$ & $2.4-23.9$ & 3092 & 398 & $2.9-25.7$ & $1.6-11.3$ & $0.032-0.252$ \\
\hline Vertical & P. ponderosa sticks array & 18 & $0.60-1.21$ & $0.076-0.152$ & $4.0-8.0$ & 630 & 442 & $5.5-8.9$ & $1.6-9.6$ & $0.011-0.064$ \\
\hline
\end{tabular}

Variables used are: $w$, foliar fuel load; $h$, fuel bed height; $\rho_{\mathrm{b}}$, fuel bed density; $S_{\mathrm{V}}$, surface area-to-volume ratio; $\rho_{\mathrm{p}}$, fuel particle density; $M$, fuel bed foliar moisture content; $U$, wind speed; $R_{\mathrm{U}}$, wind-driven fire spread rate.

Table 4. Summary of the field validation data.

\begin{tabular}{|c|c|c|c|c|c|c|c|c|c|c|c|}
\hline $\begin{array}{l}\text { Vegetation } \\
\text { Type }\end{array}$ & Fuel Complex & Country & $\begin{array}{c}\text { Main } \\
\text { Reference }\end{array}$ & $n$ & $I L(\mathrm{~m})$ & $w\left(\mathrm{~kg} \cdot \mathrm{m}^{-2}\right)$ & $h(\mathrm{~m})$ & $\rho_{\mathrm{b}}\left(\mathrm{kg} \cdot \mathrm{m}^{-3}\right)$ & $M(\%)$ & $U\left(\mathbf{k m} \cdot \mathbf{h}^{-1}\right)$ & $R_{\mathrm{U}}\left(\mathrm{m} \cdot \mathrm{s}^{-1}\right)$ \\
\hline \multirow[t]{3}{*}{ Shrubland } & Mixed heathland & Portugal & {$[18,41]$} & 12 & $20-50$ & $0.38-1.97$ & $0.25-1.90$ & $0.8-2.0$ & $50.2-101.9$ & $2.0-15.0$ & $0.020-0.333$ \\
\hline & Mixed heathland & Spain & [40] & 29 & $20-60$ & $0.47-2.67$ & $0.32-1.50$ & $0.7-3.1$ & $40.9-85.3$ & $3.0-15.0$ & $0.015-0.345$ \\
\hline & East coast dry and temperate wet heath & Australia & [39] & 3 & 30 & $0.85-2.47$ & $0.25-0.70$ & $2.8-3.5$ & $52.2-70.8$ & $6.0-15.0$ & $0.089-0.165$ \\
\hline Grassland & Rye, brown-top bent, sweet vernal and fog grass & Australia & {$[43,44]$} & 70 & 33 & $0.14-1.04$ & $0.16-0.90$ & $0.3-2.8$ & $4.5-89.1$ & $5.1-26.2$ & $0.068-2.222$ \\
\hline
\end{tabular}

Variables used are: $I L$, ignition line length; $w$, foliar fuel load; $h$, fuel bed height; $\rho_{\mathrm{b}}$, fuel bed density; $M$, fuel bed foliar moisture content; $U$, wind speed; $R_{\mathrm{U}}$, wind-driven fire spread rate.

Table 5. Evaluation metrics of models.

\begin{tabular}{|c|c|c|c|c|c|c|}
\hline Fire/Vegetation Type & $n$ & $f_{\mathrm{il}}$ & RMSE $\left(\mathrm{m} \cdot \mathrm{s}^{-1}\right)$ & $\operatorname{MAE}\left(\mathrm{m} \cdot \mathrm{s}^{-1}\right)$ & MAPE (\%) & $\operatorname{MBE}\left(m \cdot s^{-1}\right)$ \\
\hline Laboratory fires, the present model & 301 & 2.42 & 0.0341 & 0.0215 & 36.9 & 0.0001 \\
\hline Laboratory fires, the Rothermel model [23] & 301 & - & 0.0514 & 0.0328 & 48.7 & -0.0113 \\
\hline Shrubland field fires, the present model & 44 & 11.80 & 0.0798 & 0.0632 & 75.1 & -0.0002 \\
\hline Shrubland field fires, the model developed by Anderson et al. [20] A & 44 & - & 0.0970 & 0.0683 & 72.7 & 0.0463 \\
\hline Forest field fires, the present model & 46 & 4.70 & 0.0119 & 0.0090 & 54.9 & 0.00003 \\
\hline Forest field fires, the model developed by Fernandes et al. $[15]^{B}$ & 46 & - & 0.0110 & 0.0083 & 45.0 & -0.0004 \\
\hline Grassland field fires, the present model & 70 & 3.78 & 0.5558 & 0.3872 & 49.0 & 0.0002 \\
\hline Grassland field fires, the model developed by Cruz et al. [44] ${ }^{\mathrm{C}}$ & 70 & - & 0.4794 & 0.3716 & 106.0 & 0.2012 \\
\hline
\end{tabular}

${ }^{\mathrm{A}} R_{\mathrm{U}}=0.107 U_{2}^{0.994} h^{0.372} \exp \left(-0.0761 M_{\mathrm{d}}-0.00313 M_{1}{ }^{\mathrm{B}} R_{\mathrm{U}}=0.0129 U_{2}^{0.707}(100 h)^{0.188} \exp \left(-0.039 M_{\mathrm{d}}\right){ }^{\mathrm{C}} R_{\mathrm{U}}=0.129 U_{2}^{0.73} w^{-0.31} \exp \left(-0.02 M_{\mathrm{d}}\right)\right.$. Variables and abbreviations used are: $f_{\mathrm{il}}$, ignition line length factor; RMSE, root mean square error; MAE, mean absolute error; MAPE, mean absolute percentage error; MBE, mean bias error; $R_{\mathrm{U}}$, wind-driven fire spread rate; $U_{2}$, wind speed measured at a 2-m height; $h$, fuel bed height; $M_{\mathrm{d}}$, dead fine fuel moisture content; $M_{1}$, live fine fuel moisture content; $w$, foliar fuel load. 
(a)

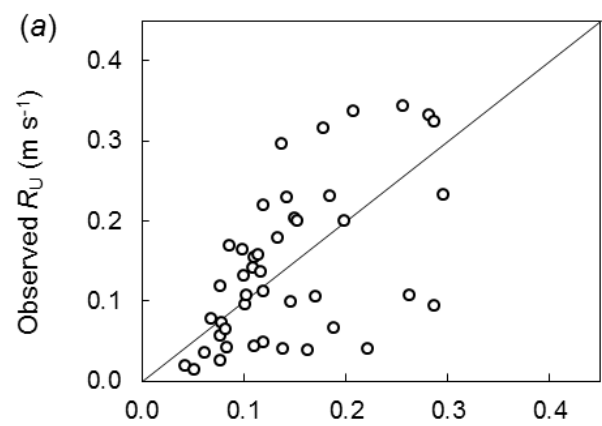

(c)

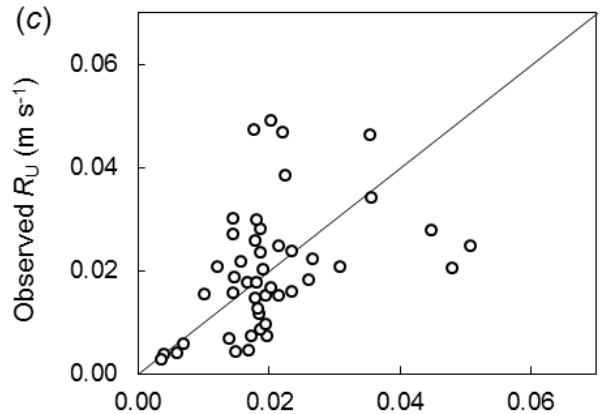

(e)

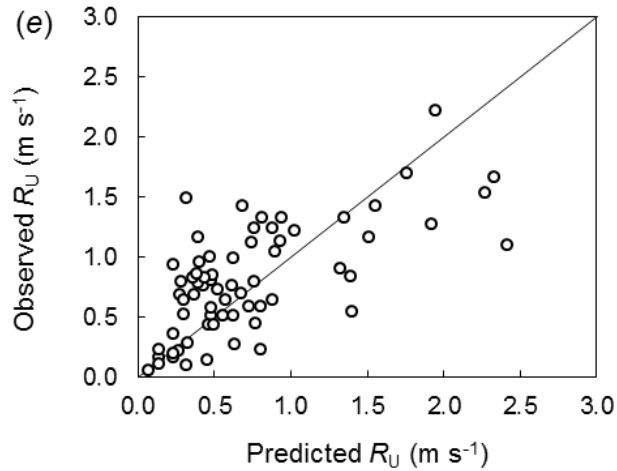

(b)

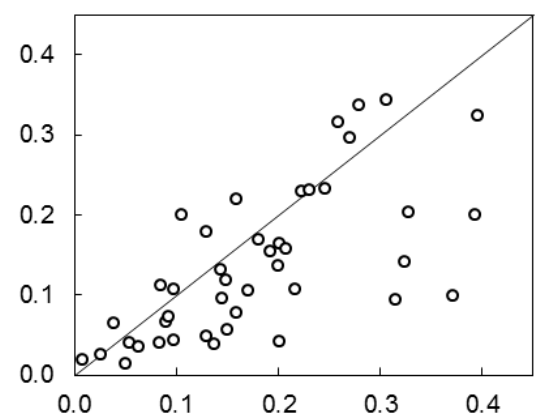

(d)

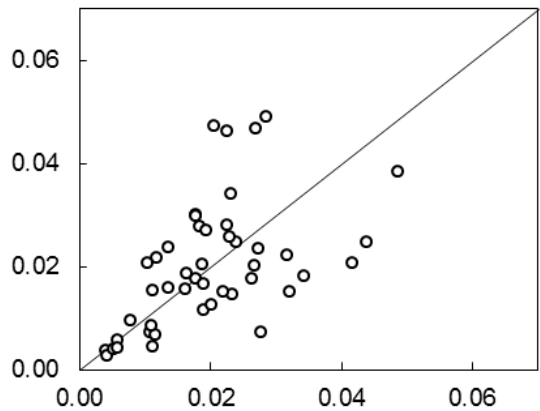

(f)

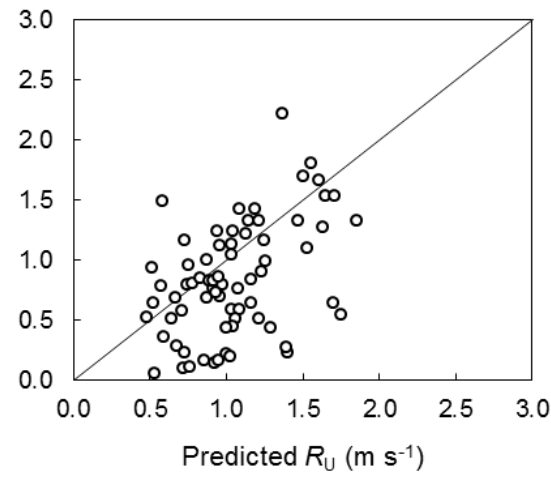

Figure 4. Observed vs. predicted wind-driven fire spread rate $\left(R_{\mathrm{U}}\right)$ for the field validation data (Table 4): (a) shrubland, the present model; (b) shrubland, the model developed by Anderson et al. [20]; (c) forest, the present model; (d) forest, the model developed by Fernandes et al. [15]; (e) grassland, the present model; and (f) grassland, the model developed by Cruz et al. [44]. Model evaluation metrics and fuel-specific formulations are given in Table 5.

Despite small differences between the $h / H_{\mathrm{f}}$ models, more pronounced at the intercept (Figure 5), the overall behavior is quite similar, even though fuel complexes are different, which provides positive indications for the suitability of the laboratory-derived model for future modelling efforts. In addition, the laboratory relationship was derived for calm conditions and the field fires were wind-driven, offering further evidence that the $h / H_{\mathrm{f}}$ ratio does not change significantly between still air and wind-assisted spread [25].

The correction factors to convert field experiments $R_{\mathrm{U}}$ to quasi-steady $R_{\mathrm{U}}$ for shrubland, forest, and grassland, yielded 1.3, 2.6, and 1.3, respectively. As a result, estimated $f_{\text {il }}$ to input in Equation (9) to predict quasi-steady $R_{\mathrm{U}}$ in these vegetation types were 15.2, 12.4, and 5.0, respectively. The exploratory functions for $f_{\mathrm{il}}$ as a function of $I L$ (Figure 6) showed that potential quasi-steady $R_{\mathrm{U}}$ was attained for much lower IL in grassland when compared to shrubland, which agrees with the robust results of Cheney and Gould [35] and Anderson et al. [20]. 


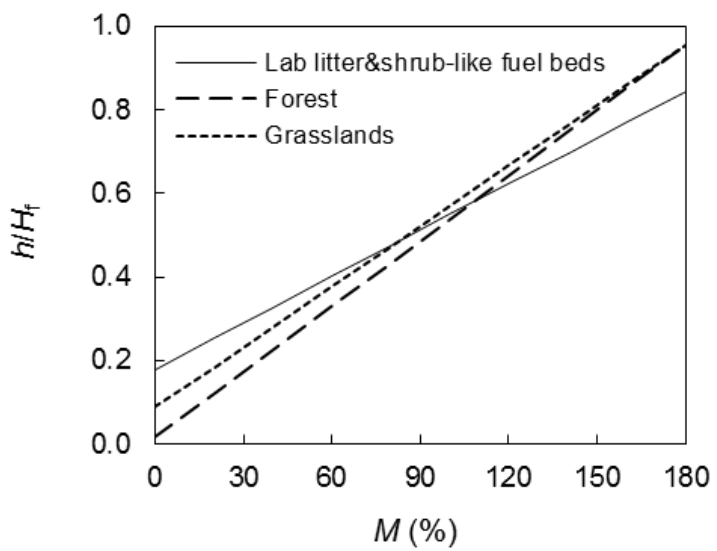

Figure 5. Models for the ratio of fuel bed height $(h)$ to flame height $\left(H_{\mathrm{f}}\right.$, measured from the base of the fuel bed) as a function of fuel complex foliar moisture content $(M)$ for: (i) laboratory litter and shrub-like fuel beds (development data tests in no-wind conditions, Table 1), fitted coefficients for Equation (4) are given in Table 2; (ii) forest (wind-driven field fires from [15], $n=60$ ), $h / H_{\mathrm{f}}=0.0168+$ $0.00522 M\left(R^{2}=0.251\right)$; and (iii) grassland (wind-driven field fires from $\left.[43,44], n=82\right), h / H_{\mathrm{f}}=0.0883+$ $0.00482 M\left(R^{2}=0.517\right) . R^{2}$, coefficient of determination; all fits were significant at $p<0.0001$.

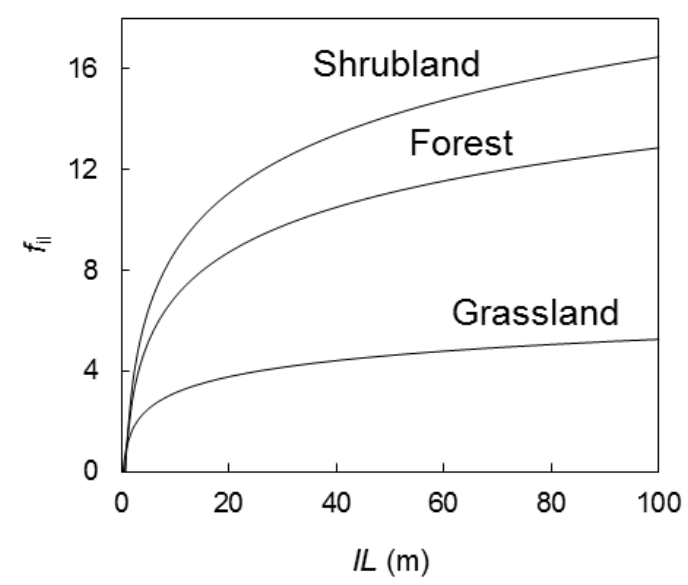

Figure 6. Exploratory functions derived from the present results and based on well-established evidence $[20,35]$ on the expected evolution of the ignition line length factor $\left(f_{\mathrm{il}}\right)$ with ignition line length (IL) for: (i) shrubland, $f_{\mathrm{il}}=1+3.362 \ln (I L)$; (ii) forest, $f_{\mathrm{il}}=1+2.578 \ln (I L)$; and (iii) grassland, $f_{\mathrm{il}}=1+$ $0.9258 \ln (I L)$. See the 'Methods' section for details on obtaining $f_{\mathrm{il}}$.

\section{Discussion}

\subsection{Model Formulation and Fire Spread Mechanisms}

We formulated, fitted, and tested a model that produces $R_{\mathrm{U}}$ estimates for flat terrain, based on the magnitude of wind speed, overall foliar fuel moisture content, vegetation height, foliar fuel load, fuel particle surface-to-mass ratio, and fireline length effect $\left(U, M, h, w, S_{\mathrm{m}}, f_{\mathrm{il}}\right)$ as input variables. This potentially expands the ability to account for variable fuel configurations and thus the scope of application in relation to the extant empirical models, which are fuel-type specific.

In Equation (3), the negative and above-unity exponents of $\dot{w}_{0}$ and $\left(h / H_{\mathrm{f}}\right)_{0}$ confirm the assumptions of model development. Hence, low $M$ (e.g., 5-12\%) enhances the effect of wind: decreased $M$-values yield small $\left(h / H_{\mathrm{f}}\right)_{0}$ ratios, i.e., flames extend much above the fuel bed, which in turn produces higher $R_{\mathrm{U}}^{\prime}$. This agrees with empirical evidence that wind has a strong influence on fire spreading over dead fuels. The formulation also accounts for why the $U$ effect is so notorious in shallow litter fuels but is more modest in deeper vegetation. For example, for $U=11 \mathrm{~km} \cdot \mathrm{h}^{-1}$, Rossa [24] obtained 
$R_{\mathrm{U}}^{\prime}=12$ in P. pinaster litter laboratory burns, whereas Fernandes [18] obtained $R_{\mathrm{U}}^{\prime}=2.8$ in shrubland fires. In fuel complexes dominated by live vegetation, which typically are tall and have high $M$, flames extend less above the fuel bed $[25,48]$ and $\left(h / H_{\mathrm{f}}\right)_{0}$ is high, diminishing the wind effect.

It may be surprising that $h / H_{\mathrm{f}}$ of field fires could be roughly predicted based on $M$ only, since flame geometry is expected to depend on other variables, such as fuel amount, but one must have in mind that some characteristics of natural vegetation vary within limited ranges around a mean value [34]. As a consequence, even when fuel characteristics are known to influence fire behavior metrics, sometimes they can be disregarded to obtain approximate estimates of a given fire behavior parameter.

The exponent of $U$ in Equation (3) cannot be compared with those from other contemporary modelling efforts that resort to a single power function of the type $U^{b}$ to predict $R_{\mathrm{U}}$, because the equation predicts how $R_{0}$ (not $R_{\mathrm{U}}$ ) is changed by wind speed by dividing the effect into several parts. Still, the fact that $b=1.71$ is much higher than found in such studies, where $b$ is generally close to unity $[15,20]$, is easy to explain. Our approach splits the influence of wind on $R_{\mathrm{U}}^{\prime}$ into three components; in such a way, its potential maximum effect $U^{1.71}$ is reduced by an amount that depends on the magnitude of the surrogate for the energy released by combustion $\dot{w}_{0}^{-1.17}$ and on how little the flames extend over the fuel bed $\left(h / H_{\mathrm{f}}\right)_{0}^{-1.17}$.

A significant feature of the model is that it separates the effects of $w$ and $h$, which are confounded and indistinguishable in other empirical formulations. The combination of these two variables, denoted as $\rho_{\mathrm{b}}$, describes fuel-bed structure reasonably well and has been identified in a number of fire experiments in different fuel types as the most relevant fuel descriptor for $R$ predictions $[20,49,50]$. Thus, although the model does not directly account for a putative effect of $\rho_{\mathrm{b}}$, this variable equals $w / h$ and thus correlates with both $h$ and $w$, which are direct or indirect inputs to Equation (3).

$R_{0}$ does not significantly depend on $w[29,34,51]$, which is mathematically explained in [52]. That is not the case of $R_{\mathrm{U}}$, since $w$ (an input to Equation (2)) influences the mechanisms of fire spread by affecting the flame tilt caused by wind. Because windless and wind-aided fire spread mechanisms have fundamental differences, empirical $R_{\mathrm{U}}$ formulations, developed specifically for wind-assisted spread but allowing extrapolation to zero $U$, may not provide accurate $R_{0}$ predictions.

\subsection{Model Performance}

We obtained improved $R_{\mathrm{U}}$ predictions in relation to Rothermel's model, even though it was developed from data from the same facilities as the trials in [33], used for laboratory evaluation. It is also important to have in mind that Rothermel's model is built on a sound basis addressing the mechanisms of fire propagation but it still requires approximately 30 fitted coefficients to obtain $R_{\mathrm{U}}$. Predictions from our model for a substantial number of field fires $(n=160)$ in shrubland, forest, and grassland compared well with those from fuel-specific formulations.

At this point, we did not achieve true model validation, because testing with independent fires required adjusting $f_{\mathrm{il}}$. Nonetheless, the model worked for an amount of independent fires $(n=461)$ seldom employed in similar studies, with no more than the need for a scale factor to account for the well-established effect of $I L$. Moreover, the independent fires spanned over a range of fuel bed properties and fire characteristics well beyond the development setting. However, model development, fitting and validation assumed a number of significant simplifications, namely the independence of $\left(h / H_{\mathrm{f}}\right)_{0}$ from fuel structure, disregard of fuels other than foliage, and constant $S_{\mathrm{m}}$ values. This provides evidence that model formulation accounts for most of the main dynamics of wind-driven fire spread and, at least, warrants additional testing in real-world fire spread situations.

Model inputs (Figure 1) do not go much beyond those required by typical field-derived fuel-specific formulations [11], which should facilitate further performance evaluation efforts by other researchers or technicians. For example, $U_{2}, h$, and $w$ are used in many empirical approaches. On the other hand, obtaining $M$ in mixtures of living and dead vegetation (Equation (5)) will create additional difficulty because beyond the need of $M_{\mathrm{d}}$, it will require measuring $M_{1}$ and evaluating $f_{\mathrm{d}}$, 
either by visual assessment or using sampling methods. Nonetheless, resorting to $M$ as an input offers the valuable advantage of accounting for the effects of drought and physiology on live vegetation, as opposed to formulations that only use $M_{\mathrm{d}}$ (implicitly assuming constant $M_{1}$ ). In a first approach, the remaining inputs can be estimated: $f_{\text {il }}$ can be obtained from the exploratory functions presented in Figure 6 , and $S_{\mathrm{m}}$ can be obtained based on typical values for foliar and herbaceous fuels (as we did in model evaluation), if necessary weighting it by fuel type in mixtures of vegetation with considerably different $S_{\mathrm{m}}$ values.

\section{Conclusions}

We developed an empirical model for the effect of wind on $R$, based on the assumption that it depends essentially on the energy released by fire in still air conditions, assumed to be proportional to $\dot{w}_{0}$, and on flame extension over the fuel bed, measured by $\left(h / H_{\mathrm{f}}\right)_{0}$. The model was fitted using laboratory experiments, and tested using a comprehensive set of independent laboratory trials and field fires in structurally distinct fuel types and covering an extensive range in fuel and fire metrics. Laboratory evaluation showed improved prediction ability in relation to Rothermel's model and predictions of field fires compared well with existing fuel-specific models. In the field fires, the data range of variables largely exceeded those used for model development, which legitimates model formulation.

The results of this study warrant further inspection in additional real-world fire spread situations for a wider range of fuel complexes. Future modelling efforts could benefit from the present evidence on the mechanisms of wind-assisted spread.

Author Contributions: Conceptualization, C.G.R. and P.M.F.; Methodology, C.G.R.; Formal Analysis, C.G.R; Investigation, C.G.R. and P.M.F.; Resources, P.M.F; Data Curation, C.G.R.; Writing-Original Draft Preparation, C.G.R. and P.M.F.; Writing-Review \& Editing, C.G.R. and P.M.F.; Funding Acquisition, C.G.R. and P.M.F.

Funding: This work was supported by Foundation for Science and Technology (FCT) under post-doctoral grant SFRH/BPD/84770/2012 (financing programs POPH and FSE) to the first author. It was also funded by the R\&D Projects BONFIRE - Global-scale analysis and modelling of fire behaviour potential, with reference POCI-01-0145-FEDER-016727 and PTDC/AAG-MAA/2656/2014, financed by the Foundation for Science and Technology (FCT) and co-financed by the European Regional Development Fund (ERDF) through COMPETE 2020 - Operational Program for Competitiveness and Internationalization (POCI); POCI-01-0145-FEDER-006958, supported by European Investment Funds by FEDER/COMPETE/POCI - Operational Competitiveness and Internationalization Program; and UID/AGR/04033/2013 supported by National Funds by FCT - Portuguese Foundation for Science and Technology.

Acknowledgments: We are grateful to Délio Sousa, Paulo Ventura, and André Rosas (University of Trás-os-Montes e Alto Douro) for assisting in some of the laboratory experimental work. The help of Fernando Frazão, David Davim, José Silva, Nuno Marcos, Rafael Figueiredo, and Raquel Roliz in fuel collection is greatly appreciated. We also thank Miguel Cruz (CSIRO) for the supply of field experimental data and comments on an early version of the manuscript.

Conflicts of Interest: The authors declare no conflict of interest.

\section{Symbols}

$a, b, c, d \quad$ fitted coefficients used in several equations

$A_{\mathrm{f}}\left({ }^{\circ}\right) \quad$ average flame angle (measured from the unburned fuel)

$f_{\mathrm{d}} \quad$ fraction of dead fuels

$f_{\text {il }} \quad$ ignition line length factor

$h(\mathrm{~m}) \quad$ fuel bed height

$H_{\mathrm{f}}(\mathrm{m}) \quad$ average flame height (measured from the base of the fuel bed)

IL $(\mathrm{m}) \quad$ ignition line length

$L_{\mathrm{f}}(\mathrm{m}) \quad$ average flame length (measured from the base of the fuel bed)

$M(\%) \quad$ fuel complex foliar moisture content (based on oven-dry weight)

$M_{\mathrm{d}}(\%) \quad$ dead fine fuel moisture content 
$M_{1}(\%) \quad$ live fine fuel moisture content

$M_{\mathrm{w}}(\%)$

$R\left(\mathrm{~m} \cdot \mathrm{s}^{-1}\right)$

$R_{0}\left(\mathrm{~m} \cdot \mathrm{s}^{-1}\right)$

$R_{\mathrm{U}}\left(\mathrm{m} \cdot \mathrm{s}^{-1}\right)$

$R_{\mathrm{U}}^{\prime}$

$R H(\%)$

$S_{\mathrm{v}}\left(\mathrm{m}^{-1}\right)$

$S_{\mathrm{m}}\left(\mathrm{m}^{2} \cdot \mathrm{kg}^{-1}\right)$

$T_{\mathrm{a}}\left({ }^{\circ} \mathrm{C}\right)$

$U\left(\mathrm{~km} \cdot \mathrm{h}^{-1}\right)$

$w\left(\mathrm{~kg} \cdot \mathrm{m}^{-2}\right)$

$w_{\mathrm{d}}\left(\mathrm{kg} \cdot \mathrm{m}^{-2}\right)$

$w_{1}\left(\mathrm{~kg} \cdot \mathrm{m}^{-2}\right)$

$\dot{w}_{0}\left(\mathrm{~kg} \cdot \mathrm{s}^{-1} \cdot \mathrm{m}^{-1}\right)$

Greek symbols

$\rho_{\mathrm{b}}\left(\mathrm{kg} \cdot \mathrm{m}^{-3}\right)$

$\rho_{\mathrm{p}}\left(\mathrm{kg} \cdot \mathrm{m}^{-3}\right)$ weighted foliar fuel moisture content

fire spread rate

basic fire spread rate (i.e., no-wind and no-slope conditions)

wind-assisted fire spread rate

adimensional wind-driven fire spread rate

relative humidity

fuel particle surface area-to-volume ratio

fuel particle surface area-to-mass ratio

air temperature

wind speed (when existing, subscript indicates measurement height)

foliar fuel load (based on oven-dry weight)

dead foliar fuel load

live foliar fuel load

rate of fuel addition to the combustion reaction per unit fireline length

fuel bed density

fuel particle density

\section{Appendix A}

Table A1. Laboratory experimental data used in model development.

\begin{tabular}{|c|c|c|c|c|c|c|c|c|c|c|c|c|c|}
\hline Fuel Bed & $\begin{array}{c}h \\
(\mathrm{~m})\end{array}$ & $\begin{array}{c}w \\
\left(\mathrm{~kg} \cdot \mathrm{m}^{-2}\right)\end{array}$ & $\begin{array}{c}\rho_{\mathrm{b}} \\
\left(\mathrm{kg} \cdot \mathrm{m}^{-3}\right)\end{array}$ & $f_{\mathrm{d}}$ & $\begin{array}{c}M \\
(\%)\end{array}$ & $\begin{array}{c}T_{\mathrm{a}} \\
\left({ }^{\circ} \mathrm{C}\right) \\
\end{array}$ & $\begin{array}{l}R H \\
(\%)\end{array}$ & $\begin{array}{c}U \\
\left(\mathbf{k m} \cdot \mathbf{h}^{-1}\right)\end{array}$ & $\begin{array}{l}H_{\mathrm{f}, 0} \\
(\mathrm{~m})\end{array}$ & $\begin{array}{l}L_{\mathrm{f}, \mathrm{U}} \\
(\mathrm{m})\end{array}$ & $\begin{array}{c}A_{\mathrm{f}, \mathrm{U}} \\
\left({ }^{\circ}\right)\end{array}$ & $\begin{array}{c}R_{0} \\
(\mathrm{~m} / \mathrm{s})\end{array}$ & $\begin{array}{c}R_{\mathrm{U}} \\
(\mathrm{m} / \mathrm{s})\end{array}$ \\
\hline \multirow{18}{*}{$\begin{array}{l}\text { Pinus pinaster Ait. } \\
\text { needles [24] }\end{array}$} & 0.056 & 0.60 & 10.7 & 1 & 13.5 & 20.5 & 70 & 3.6 & & & & 0.0027 & 0.0093 \\
\hline & 0.056 & 0.60 & 10.7 & 1 & 15.6 & 12.0 & 75 & 5.4 & & & & 0.0027 & 0.0164 \\
\hline & 0.056 & 0.60 & 10.7 & 1 & 15.5 & 21.0 & 71 & 7.2 & & & & 0.0030 & 0.0234 \\
\hline & 0.056 & 0.60 & 10.7 & 1 & 13.5 & 21.0 & 62 & 9.0 & & & & 0.0031 & 0.0256 \\
\hline & 0.056 & 0.60 & 10.7 & 1 & 13.4 & 23.0 & 62 & 10.8 & & & & 0.0029 & 0.0344 \\
\hline & 0.056 & 0.60 & 10.7 & 1 & 15.2 & 16.0 & 62 & 12.6 & & & & 0.0027 & 0.0356 \\
\hline & 0.056 & 0.60 & 10.7 & 1 & 14.0 & 19.5 & 66 & 14.4 & & & & 0.0027 & 0.0393 \\
\hline & 0.056 & 0.60 & 10.7 & 1 & 13.8 & 21.0 & 63 & 16.2 & & & & 0.0028 & 0.0468 \\
\hline & 0.054 & 0.60 & 11.1 & 1 & 16.7 & 21.1 & 56 & 3.6 & & & & 0.0023 & 0.0102 \\
\hline & 0.060 & 0.60 & 10.0 & 1 & 15.2 & 17.7 & 51 & 7.2 & & & & 0.0022 & 0.0359 \\
\hline & 0.112 & 0.80 & 7.1 & 1 & 14.4 & 16.5 & 80 & 3.6 & & & & 0.0028 & 0.0099 \\
\hline & 0.112 & 0.80 & 7.1 & 1 & 13.6 & & & 5.4 & & & & 0.0030 & 0.0148 \\
\hline & 0.112 & 0.80 & 7.1 & 1 & 11.2 & & & 7.2 & & & & 0.0035 & 0.0256 \\
\hline & 0.112 & 0.80 & 7.1 & 1 & 12.6 & & & 9.0 & & & & 0.0030 & 0.0286 \\
\hline & 0.112 & 0.80 & 7.1 & 1 & 13.6 & 17.5 & 75 & 10.8 & & & & 0.0029 & 0.0333 \\
\hline & 0.112 & 0.80 & 7.1 & 1 & 12.4 & & & 12.6 & & & & 0.0032 & 0.0391 \\
\hline & 0.112 & 0.80 & 7.1 & 1 & 13.0 & 21.5 & 55 & 14.4 & & & & 0.0032 & 0.0426 \\
\hline & 0.112 & 0.80 & 7.1 & 1 & 12.7 & 20.5 & 63 & 16.2 & & & & 0.0035 & 0.0581 \\
\hline \multirow{15}{*}{$\begin{array}{l}\text { Eucalyptus globulus Labill. } \\
\text { slash [24] }\end{array}$} & 0.075 & 0.45 & 5.9 & 1 & 7.4 & & & 3.6 & & & & 0.0032 & 0.0129 \\
\hline & 0.075 & 0.45 & 5.9 & 1 & 7.2 & & & 5.4 & & & & 0.0028 & 0.0160 \\
\hline & 0.075 & 0.45 & 5.9 & 1 & 9.4 & & & 7.2 & & & & 0.0035 & 0.0270 \\
\hline & 0.075 & 0.45 & 5.9 & 1 & 7.4 & & & 9.0 & & & & 0.0034 & 0.0465 \\
\hline & 0.075 & 0.45 & 5.9 & 1 & 7.0 & & & 10.8 & & & & 0.0031 & 0.0451 \\
\hline & 0.075 & 0.45 & 5.9 & 1 & 6.9 & & & 12.6 & & & & 0.0029 & 0.0553 \\
\hline & 0.075 & 0.45 & 5.9 & 1 & 8.8 & & & 14.4 & & & & 0.0032 & 0.0784 \\
\hline & 0.102 & 0.59 & 5.8 & 1 & 6.9 & & & 3.6 & & & & 0.0041 & 0.0143 \\
\hline & 0.102 & 0.59 & 5.8 & 1 & 7.4 & & & 5.4 & & & & 0.0032 & 0.0189 \\
\hline & 0.102 & 0.59 & 5.8 & 1 & 8.7 & 29.0 & 34 & 7.2 & & & & 0.0036 & 0.0282 \\
\hline & 0.102 & 0.59 & 5.8 & 1 & 6.3 & & & 9.0 & & & & 0.0041 & 0.0358 \\
\hline & 0.102 & 0.59 & 5.8 & 1 & 6.1 & 30.0 & 20 & 10.8 & & & & 0.0052 & 0.0596 \\
\hline & 0.102 & 0.59 & 5.8 & 1 & 13.8 & 17.5 & 82 & 12.6 & & & & 0.0020 & 0.0397 \\
\hline & 0.102 & 0.59 & 5.8 & 1 & 5.2 & & & 14.4 & & & & 0.0054 & 0.1300 \\
\hline & 0.102 & 0.59 & 5.8 & 1 & 13.1 & 19.0 & 71 & 16.2 & & & & 0.0029 & 0.0719 \\
\hline \multirow{12}{*}{ Pinus pinaster needles } & 0.119 & 1.52 & 12.9 & 1 & 18.2 & 14.0 & 58.5 & 4.0 & 0.75 & 0.80 & 60 & 0.0038 & 0.0057 \\
\hline & 0.140 & 1.69 & 12.1 & 1 & 18.1 & 14.8 & 56.5 & 4.0 & 0.85 & 1.00 & 70 & 0.0041 & 0.0061 \\
\hline & 0.148 & 1.85 & 12.5 & 1 & 19.2 & 15.1 & 57.3 & 4.0 & 0.90 & 0.95 & 70 & 0.0041 & 0.0053 \\
\hline & 0.147 & 1.85 & 12.6 & 1 & 19.1 & 15.6 & 57.6 & 4.0 & 0.85 & 1.00 & 70 & 0.0039 & 0.0055 \\
\hline & 0.125 & 1.67 & 13.4 & 1 & 19.7 & 15.7 & 58.7 & 4.0 & 0.85 & 1.00 & 70 & 0.0042 & 0.0057 \\
\hline & 0.104 & 1.50 & 14.4 & 1 & 20.3 & 15.7 & 59.1 & 4.0 & 0.65 & 0.75 & 60 & 0.0032 & 0.0052 \\
\hline & 0.098 & 1.48 & 15.2 & 1 & 21.5 & 15.8 & 58.6 & 4.0 & 0.65 & 0.75 & 60 & 0.0032 & 0.0043 \\
\hline & 0.110 & 1.64 & 14.9 & 1 & 21.9 & 16.1 & 57.9 & 4.0 & 0.70 & 0.85 & 70 & 0.0033 & 0.0043 \\
\hline & 0.124 & 1.80 & 14.6 & 1 & 22.0 & 14.5 & 55.8 & 4.0 & 0.70 & 0.90 & 70 & 0.0032 & 0.0045 \\
\hline & 0.112 & 1.79 & 16.1 & 1 & 22.9 & 15.1 & 53.5 & 4.0 & 0.70 & 0.90 & 70 & 0.0031 & 0.0047 \\
\hline & 0.101 & 1.63 & 16.2 & 1 & 22.9 & 15.4 & 53.6 & 4.0 & 0.65 & 0.70 & 70 & 0.0032 & 0.0043 \\
\hline & 0.090 & 1.46 & 16.3 & 1 & 23.1 & 15.0 & 54.6 & 4.0 & 0.60 & 0.65 & 50 & 0.0031 & 0.0044 \\
\hline
\end{tabular}


Table A1. Cont.

\begin{tabular}{|c|c|c|c|c|c|c|c|c|c|c|c|c|c|}
\hline Fuel Bed & $\begin{array}{c}h \\
(\mathrm{~m})\end{array}$ & $\begin{array}{c}w \\
\left(\mathrm{~kg} \cdot \mathrm{m}^{-2}\right)\end{array}$ & $\begin{array}{c}\rho_{\mathrm{b}} \\
\left(\mathrm{kg} \cdot \mathrm{m}^{-3}\right)\end{array}$ & $f_{\mathrm{d}}$ & $\begin{array}{c}M \\
(\%)\end{array}$ & $\begin{array}{c}T_{\mathrm{a}} \\
\left({ }^{\circ} \mathrm{C}\right) \\
\end{array}$ & $\begin{array}{l}R H \\
(\%)\end{array}$ & $\begin{array}{c}U \\
\left(\mathbf{k m} \cdot \mathbf{h}^{-1}\right)\end{array}$ & $\begin{array}{l}H_{\mathrm{f}, 0} \\
(\mathrm{~m})\end{array}$ & $\begin{array}{l}L_{\mathrm{f}, \mathrm{U}} \\
(\mathrm{m})\end{array}$ & $\begin{array}{l}A_{\mathrm{f}, \mathrm{U}} \\
\left({ }^{\circ}\right)\end{array}$ & $\begin{array}{c}R_{0} \\
(\mathrm{~m} / \mathrm{s})\end{array}$ & $\begin{array}{c}R_{U} \\
(\mathrm{~m} / \mathrm{s})\end{array}$ \\
\hline \multirow{2}{*}{$\begin{array}{c}\text { Acacia mangium Willd. } \\
\text { leaves }\end{array}$} & 0.042 & 0.53 & 12.7 & 1 & 14.1 & 15.1 & 62.8 & 8.0 & 0.30 & 0.50 & 15 & 0.0018 & 0.0184 \\
\hline & 0.050 & 0.53 & 10.6 & 1 & 13.1 & 15.8 & 64.0 & 8.0 & 0.35 & 0.50 & 15 & 0.0026 & 0.0165 \\
\hline \multirow{10}{*}{$\begin{array}{l}\text { P. resinosa Sol. ex Ait. } \\
\text { needles and vertical } \\
\text { quasi-live } P \text {. pinaster } \\
\text { branches [25] }\end{array}$} & 0.321 & 1.30 & 4.1 & 0.20 & 162.4 & 20.8 & 81.0 & 8.0 & 0.35 & 0.37 & 70 & 0.0021 & 0.0024 \\
\hline & 0.310 & 1.42 & 4.6 & 0.30 & 154.7 & 24.0 & 71.5 & 8.0 & 0.35 & 0.40 & 60 & 0.0029 & 0.0034 \\
\hline & 0.347 & 1.60 & 4.6 & 0.38 & 139.0 & 23.8 & 67.2 & 8.0 & 0.40 & 0.49 & 45 & 0.0034 & 0.0044 \\
\hline & 0.343 & 1.44 & 4.2 & 0.30 & 98.8 & 26.3 & 72.9 & 8.0 & 0.55 & 0.78 & 45 & 0.0038 & 0.0080 \\
\hline & 0.371 & 1.64 & 4.4 & 0.36 & 83.6 & 24.4 & 77.4 & 8.0 & 0.75 & 0.92 & 45 & 0.0047 & 0.0073 \\
\hline & 0.330 & 1.49 & 4.5 & 0.29 & 88.3 & 24.5 & 68.5 & 8.0 & 0.65 & 0.85 & 45 & 0.0041 & 0.0084 \\
\hline & 0.332 & 1.33 & 4.0 & 0.19 & 95.3 & 24.1 & 68.9 & 8.0 & 0.55 & 0.78 & 45 & 0.0034 & 0.0065 \\
\hline & 0.314 & 1.48 & 4.7 & 0.29 & 64.5 & 23.5 & 63.2 & 8.0 & 0.75 & 0.92 & 45 & 0.0045 & 0.0063 \\
\hline & 0.301 & 1.28 & 4.3 & 0.20 & 74.8 & 24.8 & 57.5 & 8.0 & 0.55 & 0.71 & 45 & 0.0033 & 0.0078 \\
\hline & 0.335 & 1.55 & 4.6 & 0.37 & 69.6 & 25.5 & 60.9 & 8.0 & 0.70 & 0.78 & 45 & 0.0039 & 0.0066 \\
\hline \multirow{14}{*}{$\begin{array}{l}\text { P. pinaster needles and } \\
\text { vertical quasi-live } \\
\text { P. pinaster branches [25] }\end{array}$} & 0.360 & 1.33 & 3.7 & 0.33 & 101.9 & 20.8 & 58.9 & 8.0 & 0.71 & 0.45 & 45 & 0.0021 & 0.0051 \\
\hline & 0.333 & 1.19 & 3.6 & 0.22 & 107.7 & 20.9 & 57.7 & 8.0 & 0.64 & 0.40 & 45 & 0.0020 & 0.0076 \\
\hline & 0.346 & 1.50 & 4.3 & 0.41 & 92.9 & 20.5 & 59.8 & 8.0 & 0.85 & 0.55 & 45 & 0.0023 & 0.0066 \\
\hline & 0.346 & 1.35 & 3.9 & 0.32 & 99.1 & 20.8 & 61.2 & 8.0 & 0.85 & 0.45 & 45 & 0.0022 & 0.0073 \\
\hline & 0.319 & 1.16 & 3.6 & 0.23 & 114.2 & 20.7 & 54.7 & 8.0 & 0.78 & 0.45 & 45 & 0.0019 & 0.0075 \\
\hline & 0.331 & 1.32 & 4.0 & 0.20 & 73.6 & 21.7 & 48.4 & 8.0 & 1.27 & 0.55 & 45 & 0.0029 & 0.0092 \\
\hline & 0.348 & 1.47 & 4.2 & 0.30 & 69.8 & 22.6 & 49.5 & 8.0 & 1.13 & 0.70 & 45 & 0.0032 & 0.0080 \\
\hline & 0.313 & 1.69 & 5.4 & 0.37 & 59.0 & 23.4 & 48.9 & 8.0 & 1.27 & 0.80 & 45 & 0.0036 & 0.0089 \\
\hline & 0.357 & 1.82 & 5.1 & 0.42 & 47.3 & 14.7 & 67.7 & 8.0 & 1.04 & 0.95 & 60 & 0.0049 & 0.0092 \\
\hline & 0.353 & 1.89 & 5.3 & 0.41 & 36.9 & 16.0 & 65.3 & 8.0 & 1.15 & 0.95 & 60 & 0.0051 & 0.0111 \\
\hline & 0.346 & 1.81 & 5.2 & 0.42 & 42.9 & 16.9 & 64.3 & 8.0 & 1.15 & 0.90 & 60 & 0.0048 & 0.0088 \\
\hline & 0.347 & 1.66 & 4.8 & 0.46 & 55.8 & 17.7 & 62.5 & 8.0 & 1.10 & 0.85 & 60 & 0.0050 & 0.0090 \\
\hline & 0.313 & 1.79 & 5.7 & 0.43 & 44.4 & 16.6 & 71.3 & 8.0 & 1.04 & 0.80 & 60 & 0.0043 & 0.0086 \\
\hline & 0.331 & 1.84 & 5.6 & 0.42 & 40.2 & 17.3 & 70.5 & 8.0 & 1.04 & 0.95 & 60 & 0.0051 & 0.0089 \\
\hline \multirow{6}{*}{$\begin{array}{l}\text { E. globulus leaves and } \\
\text { vertical quasi-live } \\
\text { E. globulus branches [25] }\end{array}$} & 0.340 & 1.03 & 3.0 & 0.61 & 19.6 & 21.6 & 73.0 & 8.0 & 0.80 & 2.10 & 30 & 0.0037 & 0.0095 \\
\hline & 0.375 & 1.49 & 4.0 & 0.31 & 62.2 & 23.0 & 43.7 & 8.0 & 0.60 & 1.80 & 30 & 0.0033 & 0.0084 \\
\hline & 0.367 & 1.29 & 3.5 & 0.21 & 71.8 & 23.5 & 44.3 & 8.0 & 0.65 & 1.70 & 30 & 0.0036 & 0.0081 \\
\hline & 0.382 & 1.62 & 4.3 & 0.38 & 42.3 & 21.3 & 57.6 & 8.0 & 1.00 & 1.41 & 45 & 0.0064 & 0.0097 \\
\hline & 0.371 & 1.42 & 3.8 & 0.32 & 48.7 & 22.5 & 47.9 & 8.0 & 0.75 & 1.34 & 45 & 0.0043 & 0.0102 \\
\hline & 0.354 & 1.25 & 3.5 & 0.22 & 53.0 & 23.2 & 46.1 & 8.0 & 0.65 & 1.41 & 45 & 0.0045 & 0.0105 \\
\hline \multirow{15}{*}{ E. globulus branches } & 0.404 & 0.69 & 1.7 & 1 & 12.6 & 14.9 & 58.8 & 4.0 & 1.25 & 1.50 & 70 & 0.0183 & 0.0241 \\
\hline & 0.425 & 0.79 & 1.9 & 1 & 12.8 & 14.8 & 57.2 & 4.0 & 1.50 & 1.50 & 70 & 0.0163 & 0.0235 \\
\hline & 0.418 & 0.89 & 2.1 & 1 & 12.3 & 15.6 & 59.1 & 4.0 & 1.30 & 1.60 & 70 & 0.0146 & 0.0219 \\
\hline & 0.396 & 0.79 & 2.0 & 1 & 12.8 & 16.4 & 57.9 & 4.0 & 1.10 & 1.50 & 70 & 0.0170 & 0.0261 \\
\hline & 0.426 & 0.89 & 2.1 & 1 & 12.6 & 17.1 & 58.6 & 4.0 & 1.40 & 1.70 & 70 & 0.0173 & 0.0221 \\
\hline & 0.406 & 0.69 & 1.7 & 1 & 13.2 & 17.2 & 59.6 & 4.0 & 1.20 & 1.40 & 70 & 0.0164 & 0.0191 \\
\hline & 0.249 & 0.64 & 2.6 & 1 & 12.1 & 15.5 & 55.2 & 4.0 & 0.85 & 1.10 & 80 & 0.0112 & 0.0140 \\
\hline & 0.255 & 0.73 & 2.8 & 1 & 12.4 & 15.8 & 55.3 & 4.0 & 1.10 & 1.20 & 80 & 0.0145 & 0.0158 \\
\hline & 0.257 & 0.81 & 3.2 & 1 & 12.7 & 15.8 & 58.3 & 4.0 & 1.20 & 1.30 & 80 & 0.0128 & 0.0166 \\
\hline & 0.271 & 0.81 & 3.0 & 1 & 13.4 & 15.1 & 60.7 & 4.0 & 1.10 & 1.20 & 80 & 0.0132 & 0.0149 \\
\hline & 0.256 & 0.72 & 2.8 & 1 & 13.0 & 15.4 & 61.8 & 4.0 & 0.90 & 1.10 & 80 & 0.0111 & 0.0139 \\
\hline & 0.253 & 0.64 & 2.5 & 1 & 12.9 & 15.8 & 62.1 & 4.0 & 0.85 & 1.10 & 80 & 0.0121 & 0.0147 \\
\hline & 0.244 & 0.63 & 2.6 & 1 & 13.5 & 16.0 & 60.3 & 4.0 & 0.90 & 0.95 & 80 & 0.0114 & 0.0138 \\
\hline & 0.244 & 0.73 & 3.0 & 1 & 12.4 & 16.3 & 56.1 & 4.0 & 0.85 & 1.10 & 80 & 0.0111 & 0.0139 \\
\hline & 0.245 & 0.81 & 3.3 & 1 & 12.3 & 16.5 & 55.2 & 4.0 & 1.05 & 1.20 & 80 & 0.0125 & 0.0153 \\
\hline
\end{tabular}

Variables used are: $h$, fuel bed height; $w$, foliar fuel load; $\rho_{\mathrm{b}}$, fuel bed density; $f_{\mathrm{d}}$, fraction of dead fuels; $M$, fuel bed foliar moisture content; $T_{\mathrm{a}}$, air temperature; $R H$, relative humidity; $U$, wind speed; $H_{\mathrm{f}, 0}$, flame height (measured from the base of the fuel bed) for no-wind conditions; $L_{\mathrm{f}, \mathrm{U}}$, flame length (measured from the base of the fuel bed) for wind-assisted spread; $A_{\mathrm{f}, \mathrm{U}}$, flame angle (measured from the unburned fuel) for wind-driven spread; $R_{0}$, basic fire spread rate; $R_{\mathrm{U}}$, wind-assisted fire spread rate.

\section{References}

1. Show, S.B. Climate and forest fires in northern California. J. For. 1919, 17, 965-979.

2. Curry, J.R.; Fons, W.L. Rate of spread of surface fires in the Ponderosa pine type of California. J. Agric. Res. $1938,57,239-267$. 
3. Sullivan, A.L.; Sharples, J.J.; Matthews, S.; Plucinski, M. Estimating downslope fire spread for landscape fire spread prediction. Environ. Model. Softw. 2014, 62, 153-163. [CrossRef]

4. Chatelon, F.J.; Balbi, J.H.; Morvan, D.; Rossi, J.L.; Marcelli, T. A convective model for laboratory fires with well-ordered vertically-oriented fuel beds. Fire. Saf. J. 2017, 90, 54-61. [CrossRef]

5. Cruz, M.G.; Alexander, M.E.; Sullivan, A.L. Mantras of wildland fire behavior modelling: facts or fallacies? Int. J. Wildland Fire 2017, 26, 973-981. [CrossRef]

6. Sullivan, A.L. Wildland surface fire spread modelling; 1990-2007. 1: Physical and quasi-physical models. Int. J. Wildland Fire 2009, 18, 349-368. [CrossRef]

7. Cheney, N.P.; Gould, J.S.; Catchpole, W.R. Prediction of fire spread in grasslands. Int. J. Wildland Fire 1998, 8, 1-15. [CrossRef]

8. Sullivan, A.L. Wildland surface fire spread modelling; 1990-2007. 2: Empirical and quasi-empirical models. Int. J. Wildland Fire 2009, 18, 369-386. [CrossRef]

9. Rossa, C.G.; Fernandes, P.M. On the effect of live fuel moisture content on fire rate of spread. For. Syst. 2017, 26, eSC08. [CrossRef]

10. Pastor, E.; Zarate, L.; Planas, E.; Arnaldos, J. Mathematical models and calculation systems for the study of wildland fire behavior. Prog. Energy Combust. Sci. 2003, 29, 139-153. [CrossRef]

11. Cruz, M.G.; Gould, J.S.; Alexander, M.E.; Sullivan, A.L.; McCaw, W.L.; Matthews, S. Empirical-based models for predicting head-fire rate of spread in Australian fuel types. Aust. Forest. 2015, 78, 118-158. [CrossRef]

12. McArthur, A.G. Control burning in eucalypt forest; Leaflet No. 80; Australian Forestry and Timber Bureau: Canberra, Australia, 1962.

13. Forestry Canada Fire Danger Group. Development and Structure of the Canadian Forest Fire Behavior Prediction System; Information Report St-X-3; Forestry Canada, Ed.; Forestry Canada, Science and Sustainable Development Directorate: Ottawa, ON, Canada, 1992.

14. Burrows, N.D. Fire behavior in jarrah forest fuels: 2. Field experiments. CALM Sci. 1999, 3, 57-84.

15. Fernandes, P.M.; Botelho, H.S.; Rego, F.C.; Loureiro, C. Empirical modelling of surface fire behavior in maritime pine stands. Int. J. Wildland Fire 2009, 18, 698-710. [CrossRef]

16. Cheney, N.P.; Gould, J.S.; McCaw, W.L.; Anderson, W.R. Predicting fire behavior in dry eucalypt forest in southern Australia. For. Ecol. Manag. 2012, 280, 120-131. [CrossRef]

17. McCaw, W.L. Predicting fire spread in Western Australian mallee-heath. CALM Sci. Supplement 1995, 4, 35-42.

18. Fernandes, P.M. Fire spread prediction in shrub fuels in Portugal. For. Ecol. Manag. 2001, 144, 67-74. [CrossRef]

19. Cruz, M.G.; McCaw, W.L.; Anderson, W.R.; Gould, J.S. Fire behavior modelling in semi-arid mallee-heath shrublands of southern Australia. Environ. Modell. Softw. 2013, 40, 21-34. [CrossRef]

20. Anderson, W.R.; Cruz, M.G.; Fernandes, P.M.; McCaw, L.; Vega, J.A.; Bradstock, R.; Fogarty, L.; Gould, J.; McCarthy, G.; Marsden-Smedley, J.B.; et al. A generic, empirical based model for predicting rate of fire spread in shrublands. Int. J. Wildland Fire 2015, 24, 443-460. [CrossRef]

21. McArthur, A.G. Weather and Grassland Fire Behavior; Leaflet No. 100; Australian Forestry and Timber Bureau: Canberra, Australia, 1966.

22. Burrows, N.D.; Ward, B.; Robinson, A. Fuel dynamics and fire spread in spinifex grasslands of the Western Desert. Proc. R. Soc. Queensl. 2009, 115, 69-76.

23. Rothermel, R.C. A mathematical Model for Predicting Fire Spread in Wildland Fuels; Res. Pap. INT-115; USDA Forest Service, Intermountain Forest and Range Experiment Station: Ogden, UT, USA, 1972.

24. Rossa, C.G. Dynamic model for fire behavior prediction. Ph.D. Thesis, University of Coimbra, Coimbra, Portugal, 2009.

25. Rossa, C.G.; Fernandes, P.M. Fuel-related fire-behavior relationships for mixed live and dead fuels burned in the laboratory. Can. J. For. Res. 2017, 47, 883-889. [CrossRef]

26. Rossa, C.G.; Davim, D.A.; Viegas, D.X. Behavior of slope and wind backing fires. Int. J. Wildland Fire 2015, 24, 1085-1097. [CrossRef]

27. Rossa, C.G.; Fernandes, P.M.; Pinto, A. Measuring foliar moisture content with a moisture analyzer. Can. J. For. Res. 2015, 45, 776-781. [CrossRef] 
28. Finney, M.A.; Cohen, J.D.; Forthofer, J.M.; McAllister, S.S.; Gollner, M.J.; Gorham, D.J.; Saito, K.; Akafuah, N.K.; Adam, B.A.; English, J.D. The role of buoyant flame dynamics in wildfire spread. Proc. Natl. Acad. Sci. USA 2015, 112, 9833-9838. [CrossRef] [PubMed]

29. Rossa, C.G. The effect of fuel moisture content on the spread rate of forest fires in the absence of wind or slope. Int. J. Wildland Fire 2017, 26, 24-31. [CrossRef]

30. Thomas, P.H.; Simms, D.L. A study of fire spread in forest fires. In Report on Forest Research for the Year Ended March 1963; Forestry Commission, HM Stationary Office: London, UK, 1964; pp. 108-112.

31. Rothermel, R.C.; Anderson, H.E. Fire Spread Characteristics Determined in the Laboratory; Res. Pap. INT-30; USDA Forest Service, Intermountain Forest and Range Experiment Station: Ogden, UT, USA, 1966.

32. Snowdon, P. A ratio estimator for bias correction in logarithmic regressions. Can. J. For. Res. 1991, 21, 720-724. [CrossRef]

33. Catchpole, W.R.; Catchpole, E.A.; Rothermel, R.C.; Morris, G.A.; Butler, B.W.; Latham, D.J. Rate of spread of free-burning fires in woody fuels in a wind tunnel. Combust. Sci. Technol. 1998, 131, 1-37. [CrossRef]

34. Rossa, C.G.; Fernandes, P.M. Empirical modelling of fire spread rate in no-wind and no-slope conditions. Forest Sci. 2018, 64, 358-370. [CrossRef]

35. Cheney, N.P.; Gould, J.S. Fire growth in grassland fuels. Int. J. Wildland Fire 1995, 5, 237-247. [CrossRef]

36. Wilson, R.A. Reformulation of Forest Fire Spread Equations in SI Units; Res. Pap. INT-292; USDA Forest Service, Intermountain Forest and Range Experiment Station: Ogden, UT, USA, 1980.

37. Cruz, M.G.; Gould, J.S.; Alexander, M.E.; Sullivan, A.L.; McCaw, W.L.; Matthews, S. A Guide to Rate of Fire Spread Models for Australian Vegetation; CSIRO Land and Water Flagship, and AFAC: Melbourne, Australia, 2015.

38. Albini, F.A.; Baughman, R.G. Estimating Wind Speeds for Predicting Wildland Fire Behavior; Res. Pap. INT-221; USDA Forest Service, Intermountain Forest and Range Experiment Station: Ogden, UT, USA, 1979.

39. Catchpole, W.R. Heathland Fuel and Fire Modelling. Ph.D. Thesis, Australian Defence Force Academy, University of New South Wales, Canberra, ACT, Australia, 1987.

40. Vega, J.A.; Cuinas, P.; Fonturbel, T.; Perez-Gorostiaga, P.; Fernandez, C. Predicting Fire Behavior in Galician (NW Spain) Shrubland Fuel Complexes. In Proceedings of the III International Conference on Forest Fire Research and 14th Conference on Fire and Forest Meteorology', Luso, Portugal, 16-20 November 1998.

41. Vega, J.A.; Fernandes, P.; Cuinas, P.; Fonturbel, M.T.; Loureiro, C. Fire spread analysis of early summer field experiments in shrubland fuel types of north-western Iberia. For. Ecol. Manag. 2006, 234, S1.

42. Fernandes, P.M.; Rego, F.C. Equations for estimating fuel load in shrub communities dominated by Chamaespartium tridentatum and Erica umbellata. In Proceedings of the III International Conference on Forest Fire Research and 14th Conference on Fire and Forest Meteorology, Luso, Portugal, 16-20 November 1998.

43. Cruz, M.G.; Gould, J.S.; Kidnie, S.; Bessell, R.; Nichols, D.; Slijepcevic, A. Effects of curing on grassfires: II. Effect of grass senescence on the rate of fire spread. Int. J. Wildland Fire 2015, 24, 838-848. [CrossRef]

44. Cruz, M.G.; Sullivan, A.L.; Hurley, R.J.; Plucinski, M.P.; Gould, J.S. The Effect of Fuel Load and Structure on Grassland Fire Behavior and Fire Danger - Final Report; Client Report No EP178976; CSIRO Land and Water: Canberra, Australia, 2017.

45. Clark, R.G. Threshold requirements for fire spread in grassland fuels. Ph.D. Thesis, Texas Tech University, Lubbock, TX, USA, 1983.

46. Fernandes, P.M. Upscaling the estimation of surface-fire rate of spread in maritime pine (Pinus pinaster Ait.) forest. iForest 2014, 7, 123-125. [CrossRef]

47. Willmott, C.J. Some comments on the evaluation of model performance. Bull. Am. Meteorol. Soc. 1982, 63, 1309-1312. [CrossRef]

48. Rossa, C.G.; Veloso, R.; Fernandes, P.M. A laboratory-based quantification of the effect of live fuel moisture content on fire spread rate. Int. J. Wildland Fire 2016, 25, 569-573. [CrossRef]

49. Fernandes, P.M.; Catchpole, W.R.; Rego, F.C. Shrubland fire behavior modelling with microplot data. Can. J. For. Res. 2000, 30, 889-899. [CrossRef]

50. Davies, G.M.; Legg, C.J.; MacDonald, A.J. Rate of spread of fires in Calluna vulgaris-dominated moorlands. J. Appl. Ecol. 2009, 46, 1054-1063. [CrossRef] 
51. Rossa, C.G. A generic fuel moisture content attenuation factor for fire spread rate empirical models. For. Syst. 2018, 27, e09. [CrossRef]

52. Rossa, C.G.; Fernandes, P.M. On the fire-spread rate influence of some fuel bed parameters derived from Rothermel's model thermal energy balance. Sumar. List 2018, 142, 77-80. [CrossRef]

(C) 2018 by the authors. Licensee MDPI, Basel, Switzerland. This article is an open access article distributed under the terms and conditions of the Creative Commons Attribution (CC BY) license (http://creativecommons.org/licenses/by/4.0/). 